\title{
Modeling Smoke Plume-Rise and Dispersion from Southern United States Prescribed Burns with Daysmoke
}

\author{
Gary L. Achtemeier ${ }^{1}{ }^{*}$, Scott A. Goodrick ${ }^{1}$, Yongqiang Liu ${ }^{1}$, Fernando Garcia-Menendez ${ }^{2}$, \\ Yongtao $\mathrm{Hu}^{2}$ and Mehmet Talat Odman ${ }^{2}$ \\ 1 Center for Forest Disturbance Science, USDA Forest Service, Athens, GA 30602, USA; \\ E-Mails: sgoodrick@fs.fed.us (S.A.G.); yliu@fs.fed.us (Y.L.) \\ 2 School of Civil and Environmental Engineering, Georgia Institute of Technology, \\ Atlanta, GA 30332-0512, USA; E-Mails: fernandog@gatech.edu (F.G.-M.); \\ yh29@mail.gatech.edu (Y.H.); odman@gatech.edu (M.T.O.) \\ * Author to whom correspondence should be address; E-Mail: gachtemeier@fs.fed.us; \\ Tel.: +1-706-559-4239; Fax: +1-706-559-4317.
}

Received: 1 June 2011; in revised form: 8 July 2011 / Accepted: 22 July 2011 /

Published: 19 August 2011

\begin{abstract}
We present Daysmoke, an empirical-statistical plume rise and dispersion model for simulating smoke from prescribed burns. Prescribed fires are characterized by complex plume structure including multiple-core updrafts which makes modeling with simple plume models difficult. Daysmoke accounts for plume structure in a three-dimensional veering/sheering atmospheric environment, multiple-core updrafts, and detrainment of particulate matter. The number of empirical coefficients appearing in the model theory is reduced through a sensitivity analysis with the Fourier Amplitude Sensitivity Test (FAST). Daysmoke simulations for "bent-over" plumes compare closely with Briggs theory although the two-thirds law is not explicit in Daysmoke. However, the solutions for the "highly-tilted" plume characterized by weak buoyancy, low initial vertical velocity, and large initial plume diameter depart considerably from Briggs theory. Results from a study of weak plumes from prescribed burns at Fort Benning GA showed simulated ground-level $\mathrm{PM}_{2.5}$ comparing favorably with observations taken within the first eight kilometers of eleven prescribed burns. Daysmoke placed plume tops near the lower end of the range of observed plume tops for six prescribed burns. Daysmoke provides the levels and amounts of smoke injected into regional scale air quality models. Results from CMAQ with and without an adaptive grid are presented.
\end{abstract}


Keywords: smoke; prescribed fires; plume model; air quality

\section{Introduction}

The forests of the southern United States (the 13 States roughly south of the Ohio River and from Texas to the Atlantic Coast) comprise one of the most productive forested areas in the United States. Approximately 200 million acres ( 80 million ha) or 40\% of U.S. forests are found within this area-comprising only $24 \%$ of the U.S. land area [1]. These forests are dynamic ecosystems characterized by rapid growth within a favorable climate. The fire-return interval of every $3-5$ years is the highest in the nation [2].

Approximately six million acres (2.4 million ha) of forest and agricultural land are burned each year in the southern United States to accomplish a number of land management objectives [3]. Smoke from these burns poses a threat - either as a nuisance, visibility, or transportation hazard [4,5], and/or as a health hazard [6]. The hazard can be local and/or regional depending on the number of prescribed burns being conducted on a given day.

Fires have been found to be an important source of $\mathrm{PM}_{2.5}$ (particulate matter with aerodynamic diameter of equal to or less than 2.5 micrometers) [7]. Forestry smoke in the southern United States contributes significantly to the budget of particulate matter in the atmosphere and efforts have been undertaken to include the smoke in regional air quality models [8-12]. Recent studies suggest that prescribed burning alone may be contributing up to $30 \%$ of the annual $\mathrm{PM}_{2.5}$ mass in the Southeastern United States [13] and may be the leading cause of high $\mathrm{PM}_{2.5}$ episodes in the region [14]. For example, the simulation studies of a number of prescribed burns in the Southern U.S. with the Community Multiscale Air Quality model (CMAQ, $[15,16]$ ) indicated that smoke plumes caused severe air quality problems in downwind metropolitan areas with the ground $\mathrm{PM}_{2.5}$ concentrations much higher than the daily (24-h) US National Ambient Air Quality Standard.

Regional scale air quality models require knowledge of how much smoke is discharged into the atmosphere as the plume rises to some maximum height. Plume rise ranges from hundreds of meters for prescribed fires to thousands of meters for wildfires. However, plume rise and dispersion from wildland fires is difficult to model because of complex plume dynamics. For example, Figure 1 shows the GOES satellite image of the plume produced by the 27 February 2004 Magazine Mountain, AR, prescribed burn (red area) at 1515 LST. The image, showing an expanding single plume transported towards northwestern Arkansas by the prevailing wind, gives an impression of being from a "scaled-up" version of an industrial plume. However, Figure 2 reveals a complex structure of merging multiple updraft "cores" when the plume is viewed from the ground.

Clearly the updraft structure of wildland fire plumes must be modeled correctly if accurate estimates for plume rise, amounts and heights of smoke injection in the atmosphere, and dispersion are to be made available for air quality models. Full-physics smoke plume models such as the active tracer high-resolution atmospheric model (ATHAM) [17,18] can model the complexity of wildland fire plume structures. Reference [19] simulated a prescribed burn in northwestern Washington which closely approximated measured elevations and concentrations of smoke. However, if the objective is to 
simulate hundreds of prescribed burns daily in the southern United States, much simpler modeling approaches would be required to make available plume rise data for operational air quality models such as CMAQ [16], its adaptive grid version [20] or WRF-Chem [21] for predicting air quality and assessing pollution control strategy development, exposure, impacts of regional climate change, and etc.

Figure 1. 1515 LST GOES image of the smoke plume from the 27 February 2004 Magazine Mountain, AR, prescribed burn (red area).

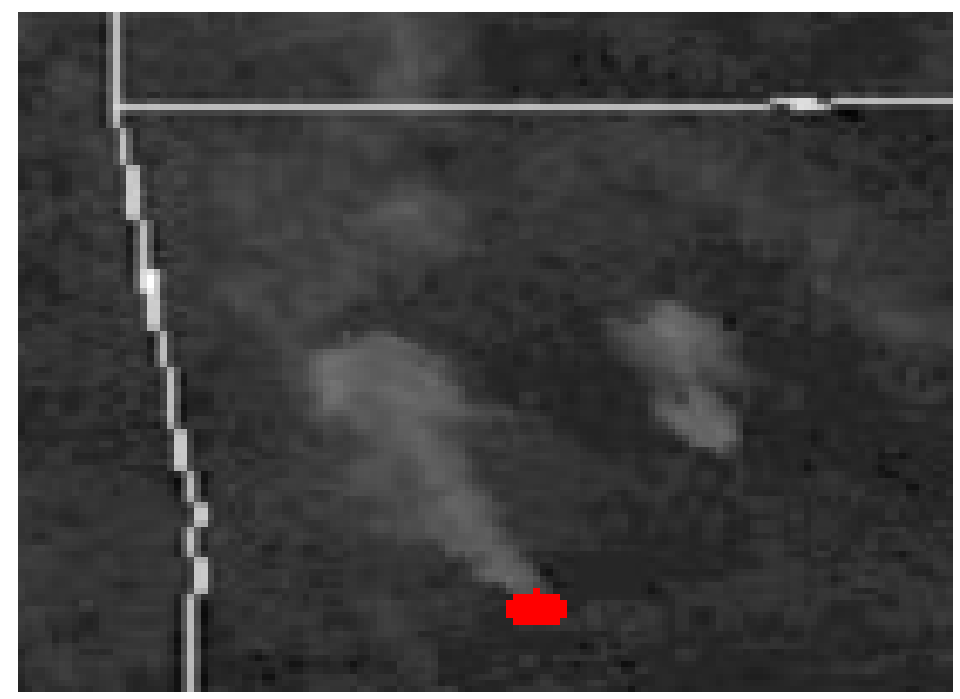

Figure 2. Photo-images of the smoke plume above the 27 February 2004 Magazine Mountain, AR, prescribed burn.

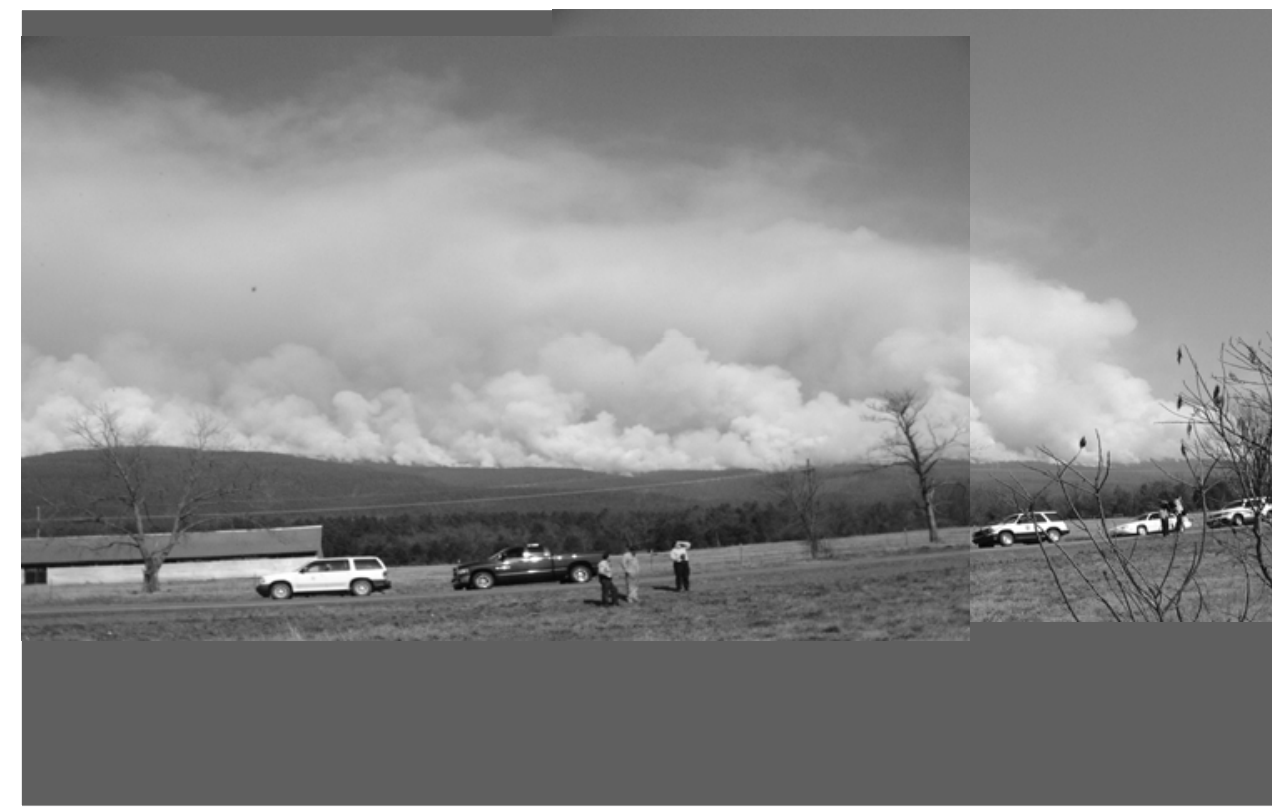

Reference [22] linked fuels information with meteorological data through VSMOKE, a Gaussian "screening" model for local smoke dispersion. VSMOKE attempted to account for plume complexity by placing $40 \%$ of smoke at the ground as an initial step. The Florida Fire Management Information System $[23,24]$ merges the cross flow Gaussian horizontal dispersion properties of VSMOKE with 
three dimensional trajectories produced by HYSPLIT [25] to estimate smoke plume movement and the ground-level impact of $\mathrm{PM}_{2.5}$ concentrations on potentially hazardous visibility reductions.

This paper describes "Daysmoke", an empirical-stochastic plume model designed to simulate multiple-core updraft smoke plumes from prescribed burns. Daysmoke is an extension of ASHFALL, a plume model developed to simulate deposition of ash from sugar cane fires [26]. As adapted for prescribed fire, Daysmoke consists of three models - an entraining turret model that calculates plume pathways, a particle trajectory model that simulates smoke transport through the plume pathways, and a meteorological "interface" model that links these models to weather data from high-resolution numerical weather models.

Model theory and assumptions are described in the next section. Results from validation studies for simulating weak plumes and applications to regional scale air quality modeling follow.

\section{Model Theory and Description}

Conceptually, a rising convective plume driven by heat from combustion entrains ambient air which adds to the plume mass while modulating its buoyancy and vertical velocity. Some plume air and particulate matter are detrained into the ambient air creating a "pall" of smoke extending downwind beneath the visible plume. The growing smoke plume ascends to near the top of the mixing layer. If the smoke plume is relatively weak (cool and slow-rising), all or part of it may be captured, torn apart, and dispersed by turbulence within the mixed layer before it rises to an altitude of thermal equilibrium. If the convective smoke plume is strong, most of the smoke may be ejected into the free atmosphere far above the top of the mixed layer with little or no smoke remaining to be dispersed within the mixed layer.

\subsection{The Entraining Turret Model}

From photogrammetric analysis of video footage of smoke plumes from burning sugar cane, reference [27] determined that a rising smoke plume could be described by a train of rising turrets of heated air that sweep out a three-dimensional volume defined by plume boundaries on expanding through entrainment of surrounding air through the sides and bottoms as they ascend (Figure 3). The change in the volume $(V)$ of radius $(r)$ and height $(h)$ of a rising turret by entrainment of ambient air as it passes from height $z-1$ to $z$ is,

$$
\begin{aligned}
& V_{z}=V_{z-1}+\Delta V \\
& \text { where } \\
& \Delta V=\pi(r+\Delta r)^{2}(h+\Delta h)-\pi r^{2} h
\end{aligned}
$$

and is distributed over three parts: (1) an annulus around the original cylinder; (2) a cylinder added to the bottom of the original cylinder; and (3) an annulus around the added cylinder as shown by the inset in Figure 3. 
Figure 3. A schematic showing the boundaries of a smoke plume defined by rising, entraining turrets. Inset: three components of an expanding cylinder: (1) an annulus around the original cylinder; (2) a cylinder added to the original cylinder; and (3) an annulus around the added cylinder.

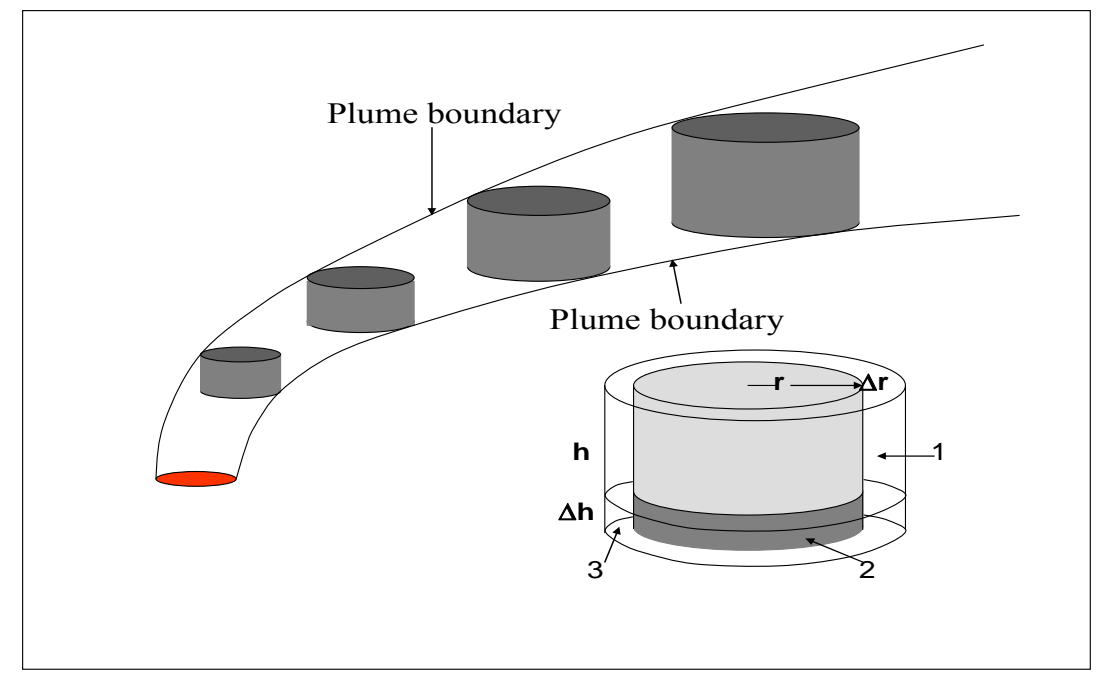

Entrainment of heat and momentum (horizontal and vertical) is a function of the downwind tilt of the plume. For example, if the horizontal wind speed is zero (the plume rises vertically), all of the material entrained through the bottom and top of the turret is plume air while entrainment of ambient air takes place through the sides. As the plume tilts in the presence of wind, more ambient air is entrained through the bottom and top of the turret until, if the plume blows horizontally, all air entrained into the turret is ambient air.

Let $Q_{e}$ represent an ambient constituent, and $Q_{z-1}$ represent the smoke plume constituent surrounding the turret at level $z-1$. The constituent $Q_{z}$ at level $z$ resulting from the mixing of the original turret with the entrained volume of mixed constituents is,

$$
Q_{z} V_{z}=Q_{z-1} V_{z-1}+Q^{\prime} \Delta V
$$

where $Q^{\prime}$ is found by weighting annulus 1 by $Q_{e}$, weighting cylinder 2 by $a_{1} Q_{z-1}+a_{2} Q_{e}$, and weighting annulus 3 by $0.5\left(a_{1} Q_{z^{-1}}+a_{2} Q_{e}+a_{3} Q_{e}\right)$ This definition for $Q^{\prime}$ requires that all air entrained into annulus 1 carries the ambient constituent; air entrained into cylinder 2 is a weighted sum of ambient and plume constituents; and air entrained into annulus 3 is the average of the mixture entrained into cylinder 2 and the ambient constituent. The three constants are chosen so that $a_{3}=a_{1}+$ $a_{2}=1$. Furthermore,

$$
a_{2}=\frac{2}{\pi} A \tan \left|\frac{s}{w}\right| ;(w \neq 0)
$$

where $s$ is the horizontal wind speed and $w$ is the plume vertical velocity. From Equation (3), if the horizontal wind is zero, the plume stands vertically, $a_{2}=0, a_{1}=1$, and entrainment from below is plume air. If the vertical velocity approaches zero, the plume drifts horizontally, $a_{2}=1, a_{1}=0$, and entrainment from below is ambient air. If $s=w$, the plume bends over to a 45 degree orientation, $a_{2}=0.5, a_{1}=0.5$, and entrainment is equally divided between ambient and plume air. 
The derivation of the plume pathways is subject to two assumptions needed to make the problem tractable. First, changes in volume are equally distributed between deepening and expanding the turret. Second, the changes in volume will be functions of the rate of turret rise. Therefore,

$$
\Delta h=\Delta r=e w_{z-1} \Delta t
$$

where $e$ is an entrainment coefficient. This assumption is equivalent to the definition for entrainment in the early rising stages of bent-over plumes [28]. Inclusion of (4) into Equations (1) and (2) gives a general algorithm for turret growth and for the evolution of constituents within the turret,

$$
Q_{z} V_{z}=Q_{z-1} V_{z-1}+\pi\left\{\begin{array}{l}
\left(e w_{z-1} \Delta t\right)\left[r^{2}\left(a_{1} Q_{z-1}+a_{2} Q_{e}\right)+2 r h Q_{e}\right]+\left(e w_{z-1} \Delta t\right)^{2}\left[2 r \left(a_{1} Q_{z-1}\right.\right. \\
\left.\left.+a_{2} Q_{e}+Q_{e}\right) / 2+h Q_{e}\right]+\left(e w_{z-1} \Delta t\right)^{3}\left(a_{1} Q_{z-1}+a_{2} Q_{e}+Q_{e}\right) / 2
\end{array}\right\}
$$

Setting $Q=T$ (temperature) in Equations (5) yields an equation for turret temperature for buoyancy calculations. Setting $Q=(u, v, w)$ (any of the velocity components) yields an equation for plume drift. Setting $Q=1$ yields an equation for the volume growth of the turret.

Initial conditions for plume temperature, rise rate, and volume start the plume rising through a veering/shearing horizontal wind field within a stratified atmosphere. Once the initial conditions are specified, Equation (5) is solved numerically to yield the plume pathway (Figure 3). In addition, the rise rate is adjusted for buoyancy through

$$
w_{z}=w_{z-1}+g \frac{T_{z}-T_{e}}{T_{e}}\left(\frac{\Delta z}{w_{z-1}}\right)
$$

where $g$ is the acceleration of gravity and $T_{e}$ is the ambient temperature.

Equation (5) does not include adiabatic expansion of the rising plume. For the vast majority of prescribed burns in the southeastern United States (for which plume tops are less than $2 \mathrm{~km}$ ), scale analysis shows that omission of adiabatic expansion leads to errors in the calculation of plume expansion of less than 3\%-an error far smaller than uncertainties in the measurement of fuel characteristics. However, should Daysmoke be used in modeling of large plumes from wildfires, the errors of omission of adiabatic expansion can become significant - perhaps as large as $30 \%$ for plumes growing above $10 \mathrm{~km}$. Therefore adiabatic expansion is calculated from [29],

$$
d(\ln V)=-2.48 d(\ln T)
$$

where the change in $T$ is the adiabatic temperature decrease the plume encounters on rising through a depth $z$.

Moist processes activate a simple cloud parameterization in Daysmoke. A cumulus cloud forms when the moisture (mixing ratio) within a rising, entraining turret exceeds the saturation mixing ratio calculated for the turret temperature. Both turret temperature and mixing ratio are calculated via Equation (5). The entire turret is assumed to be saturated. All liquid water remains within the cloud. The cloud ascends by a weighted average of the dry and moist adiabatic lapse rates calculated for the rising turret at its temperature and pressure. The cloud top is the elevation where the cloud mixing ratio falls below the saturation mixing ratio at plume temperature and pressure. Though adequate for shallow cumulus clouds that may form over prescribed burn plumes, the cloud parameterization is not adequate for modeling deep, precipitating pyro-cumuli that form on occasion above intense wildfires. 
In addition to ambient weather data, Equation (5) must be supplied with the entrainment coefficient (e) and initial values for the plume - effective plume diameter $\left(D_{0}=2 r_{0}\right)$, vertical velocity $\left(w_{0}\right)$, and the difference between plume and ambient temperatures $\left(\Delta T_{0}\right)$. The effective plume diameter is defined as the diameter a plume would have if emissions from an irregular-shaped burning area were spread over a circular area.

Observations of plumes from large-perimeter prescribed fires reveal the presence of several updraft cores or subplumes. These updraft cores may vary in size depending on the type, loading, and distribution of various fuels. Multiple-core updraft plumes, being smaller in diameter than a single core updraft plume, would be more impacted by entrainment and thus would be expected to grow to lower altitudes. If the effective plume diameter and initial vertical velocity are replaced by initial volume flux,

$$
f_{0}=\frac{\pi}{4} D_{0}^{2} w_{0}
$$

then the volume fluxes of the individual updraft cores may be defined subject to the constraint that

$$
f_{k}=f_{0} \frac{\left(0.01+\operatorname{ran}_{k}\right)}{\sum_{k=1}^{n}\left(0.01+r a n_{k}\right)}
$$

where $\operatorname{ran}_{k}$ is a random number $0<\operatorname{ran}_{k}<1$. The 0.01 is summed with the random number to render the updraft core diameter unequal to zero. Thus Daysmoke can be set to create simultaneous plume pathways for any number of updraft cores. The caveat is that $n$ and $f_{k}, k=1, \ldots, n$ are unknown. The $f_{k}$ are estimated through the random number $r a_{k}$; however, no mechanism to determine $n$ exists in Daysmoke. Equation (5) needs $D_{0 k}$ which must be calculated from each $f_{k}$. The effective plume diameter can be calculated from each updraft core volume flux by

$$
D_{0 k}=\left(\frac{4 f_{k}}{\pi w_{0}}\right)^{1 / 2}
$$

Defining what constitutes updraft cores is complicated by the merging convective sub-plumes often observed with prescribed burns (Figure 2). Thus the multiple-core updraft capability of Daysmoke remains an oversimplification of complex plume structures from prescribed burns. It becomes convenient to assert that a particular plume "behaves as an $n$-core updraft plume" even though the number of observed updraft cores may differ from $n$.

The entrainment coefficient is calculated internally in Daysmoke. For calm air and neutral stratification, reference [28] found entrainment coefficients for vertical plumes from industrial stacks to range from 0.080 for "jets" (high momentum plumes of low buoyancy) to 0.155 for buoyant plumes. For bent-over plumes, Briggs reported entrainment coefficients in the range from 0.52 to 0.66 . Thus, for the full range of buoyant plumes (from erect through bent-over), entrainment coefficients vary from 0.155 to 0.66 . Let the entrainment coefficient be proportional to a plume "bent-overness" index $B_{0}$ defined as

$$
B_{0}=\frac{\Delta x}{\Delta y}=\frac{S}{w_{0}}=\frac{S}{D_{0 k}} \frac{D_{m}}{S_{m}}=10 \frac{S}{D_{0 k}} \propto e_{k}
$$


For prescribed burns, bent-overness can be represented as the ratio of the strength of the transport wind $S$ with the strength of the plume as given by $w_{0}$. However, $w_{0}$ is fixed in Daysmoke and the strength of the plume is better represented by the effective plume diameter $D_{0}$. Let the ratio $D_{m} / S_{m}$ represent a scaling factor determined by the range of $S\left(0<S<20 \mathrm{~ms}^{-1}\right)$ and of $D(0<D<200 \mathrm{~m})$ for prescribed burns. The range of $B_{0}$ is subject to the constraint that $0.155<e_{k}<0.66$. Thus $e_{k}$ becomes a dynamic variable that changes during the course of the day as the depth of the mixing layer and wind speeds change and during the course of the burn as plume conditions change.

Figure 4 maps entrainment coefficients for the ranges of transport wind speeds and initial plume diameters described above. Most of the area is assigned the maximum entrainment coefficient, $e_{k}=0.66$ (light gray area) meaning most prescribed burns fit the bent-over designation. However, for larger diameter burns and/or weak to moderate transport wind speeds, the entrainment coefficient is variable within the range defined by the medium gray area.

Figure 4. Entrainment coefficient as a function of transport wind speed and initial plume diameter.

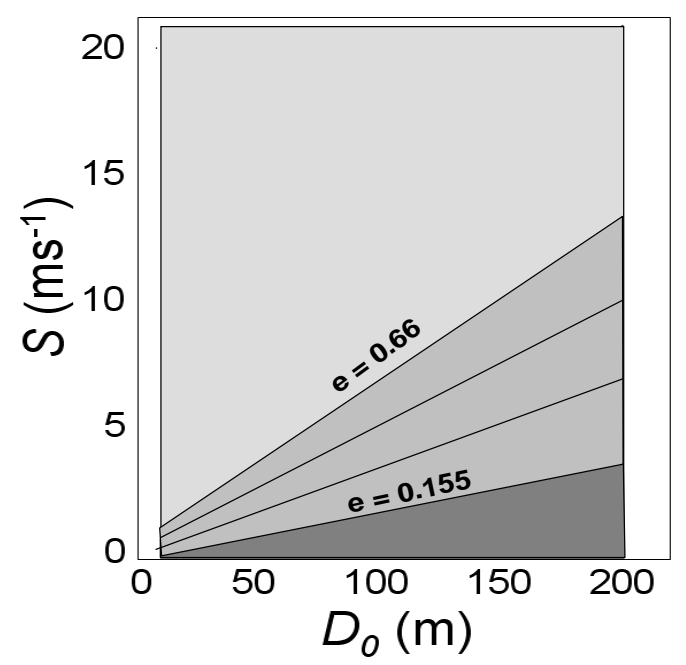

\subsection{The Detraining Particle Model}

Particles are released at the base of the multiple-core updraft plumes defined by the entraining turret module. Each particle represents a pre-assigned mass of smoke particulate matter. The particles ascend through each plume at the mean velocity components that define the three-dimensional wind speed for each level of the entraining turret module. The particles are spread laterally as the plume widens. At each time step there is added to these velocities a stochastic component that approximates turbulent spreading of smoke as it rises.

The location of a particle over an interval of time, $\Delta \mathrm{t}$, as it traverses the plume volume is given by,

$$
\begin{aligned}
x^{t} & =x^{t-1}+\left[u+2 e\left(0.5-\operatorname{ran}_{u}\right)\right] \Delta t \\
y^{t} & =y^{t-1}+\left[v+2 e\left(0.5-\operatorname{ran}_{v}\right)\right] \Delta t \\
z^{t} & =z^{t-1}+\left[w+w_{f}+2 e\left(0.5-\operatorname{ran}_{w}\right)\right] \Delta t
\end{aligned}
$$


where the entrainment coefficient $e$ in the stochastic term links particle spread with plume spread calculated in the entraining turret module. Here $\operatorname{ran}_{k}$ is a random number $0<\operatorname{ran}_{k}<1$. The variable $w_{f}$ is the fall speed (terminal velocity) of the particle.

Each particle is tracked through the plume volume until it is discharged into the free atmosphere by either (1) detrainment across plume boundaries, (2) plume capture by convective circulations, or (3) discharge through the plume top when plume vertical velocity falls below a threshold vertical velocity $w_{c}$.

\subsection{The Meteorological Interface Model}

The interface model can be of any design and complexity but, for operational considerations, it has been kept relatively simple. The interface model links Daysmoke with hourly vertical profiles of weather data taken from numerical weather prediction models. These data are hourly averages and do not represent high frequency processes that mix and disperse smoke within the boundary layer. Therefore the interface model includes a simple formulation for deep convective mixing.

After a particle is discharged from the plume, the change in its position is given by,

$$
\begin{aligned}
& x^{t}=x^{t-1}+\left[u+u_{s}+u_{c e}\right] \Delta t \\
& y^{t}=y^{t-1}+\left[v+v_{s}+v_{c e}\right] \Delta t \\
& z^{t}=z^{t-1}+\left[\left(w_{a}+w_{f}\right)+w_{s}+w_{c e}\right] \Delta t
\end{aligned}
$$

where the velocity components $(u, v)$ represents the steady part of the wind taken from the profiles of hourly weather data and subscripts $s$ and $c e$ represent small scale and convective mixing. In addition, $w_{a}$ represents the hourly vertical velocity of the ambient air and $w_{f}$ is the terminal velocity of the particle. Small scale mixing is stochastic. However, unrealistic concentrations of particles can occur just below the mixing height where there exist steep gradients in mixing. Thus, in Daysmoke,

$$
\begin{aligned}
& u_{s}=c_{s} 2\left(0.5-\operatorname{ran}_{u}\right) \\
& v_{s}=c_{s} 2\left(0.5-\operatorname{ran}_{v}\right) \\
& w_{s}=0
\end{aligned}
$$

where $\mathrm{ran}_{u}$ and $\mathrm{ran}_{v}$ are random numbers and $c_{s}$ is the small scale mixing coefficient.

The formulation for convective circulations is described in Appendix A. A string of two-dimensional mass conservative sinusoidal circulation cells oriented normal to the mean wind vector within the mixing layer and with a translation speed equal to the mean wind vector describe the convective boundary layer. The cells are mutually independent—amplitude, phase, wavelength and time history may differ. The equations in Appendix A yield the convective velocity components $\left(u_{c e}, v_{c e}, w_{c e}\right)$ for each particle subject to knowledge of the reference rotor velocity, $w_{r}$, for a mixing layer depth of $1 \mathrm{~km}$.

\section{Model Analysis (FAST Analysis and Comparison with Briggs Theory)}

\subsection{FAST Analysis}

Table 1 lists coefficients, the range of values, the assigned values and the expected impacts on plume height (P. Hgt) and ground-level concentrations of particulate matter (GLC). The ranges of 
values have been determined through approximately 200 simulations to define "reasonable" facsimiles of prescribed fire smoke plumes.

Table 1. Assigned coefficients and constants and the expected impact on Daysmoke.

\begin{tabular}{clcccc}
\hline Constant & \multicolumn{1}{c}{ Definition } & $\begin{array}{c}\text { Range } \\
\text { of Value }\end{array}$ & $\begin{array}{c}\text { Assgn } \\
\text { Value }\end{array}$ & $\begin{array}{c}\text { Impact } \\
\text { P Hgt. }\end{array}$ & GLC \\
\hline$n($ none $)$ & updraft core number & $1-10$ & user input & major & major \\
$c_{s}\left(\mathrm{~ms}^{-1}\right)$ & lateral plume spread & $0.2-0.5$ & 0.30 & none & major \\
$\mathrm{W}_{\mathrm{c}}\left(\mathrm{ms}^{-1}\right)$ & threshold velocity & $0.1-1.0$ & 0.3 & none & none \\
$\mathrm{W}_{\mathrm{f}}\left(\mathrm{ms}^{-1}\right)$ & particle terminal velocity & - & 0.0002 & none & none \\
$\mathrm{W}_{\mathrm{r}}\left(\mathrm{ms}^{-1}\right)$ & max rotor velocity & $0.5-2.0$ & 1.0 & none & major \\
\hline
\end{tabular}

The updraft core number $n$ ranges between one and ten for prescribed burns typical of the southern United States. The updraft core number is specific to each burn and is critical for determining plume height and ground-level smoke concentration.

The small scale mixing coefficient $c_{s}$ is the only mechanism in Daysmoke for the horizontal spread (normal to the plume axis) of the smoke plume. The simulations determined that the small scale mixing coefficient must fall in the range $0<c_{s}<1$. There was no lateral plume spread with $c_{s}=0$. Simulations with $c_{s}=1$ spread the plume too broadly with ground-level smoke concentrations too low as compared with observed concentrations. A more realistic range for $c_{s}$ is $0.2<c_{s}<0.5$. Other factors of plume structure, such as the definition and persistence of convective eddies in vertical cross sections of smoke plumes simulated by Daysmoke, support the choice of $c_{s}=0.3$.

The threshold vertical velocity ranges between $0.1<w_{c}<1.0 \mathrm{~ms}^{-1}$. It was found that vertical velocity profiles for strong plumes that penetrate into stable airmasses above the mixing height typically decline the final meter per second over a short distance-usually less then $20 \mathrm{~m}$. Weak plumes that do not penetrate above the mixing height are broken up by turbulence and dispersed within the mixing layer. Thus the choice for $w_{c}$ for either strong or weak plumes has little impact on plume height or ground-level smoke concentrations.

The detraining particle module does require specification for two variables: terminal velocity $w_{f}$ and threshold vertical velocity $w_{c}$. In Daysmoke, the terminal velocity is $w_{f}=-0.0002 \mathrm{~ms}^{-1}$. For the range of applications of Daysmoke, $w_{f}$ is negligible and has no impact on model calculations nor smoke sedimentation.

The expected range for the reference rotor velocity for a mixing layer of depth $1 \mathrm{~km}$ lies between $0.5<w_{r} 2.0 \mathrm{~ms}^{-1}$. Choosing $w_{r}$ too small reduces the rate smoke is transported from aloft to the ground thus yielding smoke concentrations that are too small relative to observations. Simulation results suggest $w_{r}=1.0 \mathrm{~ms}^{-1}$.

Given assigned values for the coefficients in Table 1, only the updraft core number remains to be determined. Factors contributing to updraft core number include: size of the burn, shape of burn area, heterogeneity of fuels, fuel type, moisture, and loadings, distribution of fire on landscape, amount of fire on landscape, distribution of canopy gaps, transport wind speed, and mixing layer depth. The updraft core number is critical for modeling plume top height and ground-level smoke concentrations.

The relative impacts of these coefficients on plume height (second to the last column of Table 1) were assigned following a Fourier Amplitude Sensitivity Test (FAST) applied to a larger set of model 
coefficients (Table 2) derived from an earlier version of Daysmoke. (Note that the coefficient names in Table 2 do not necessarily correspond to the coefficient names in Table 1.)

Table 2. Parameters used in the FAST sensitivity analysis for Daysmoke. The ranges shown for $\mathrm{D}_{\mathrm{f}}, \mathrm{T}_{\mathrm{z}}$, and $\mathrm{V}$ are relative changes.

\begin{tabular}{|c|c|l|c|c|c|}
\hline Model & Parameter & Meaning & Average & Range & Unit \\
\hline ETM & $\mathrm{C}_{\mathrm{e}}$ & Entrainment coefficient & 0.18 & $0.1 \sim 0.5$ & - \\
\hline \multirow{5}{*}{ DPM } & $\mathrm{C}_{\mathrm{p}}$ & Plume detrainment coefficient & 0.03 & $0.01 \sim 0.2$ & - \\
\cline { 2 - 6 } & $\mathrm{C}_{\mathrm{u}}$ & Air horizontal turbulence coefficient & 0.15 & $0.1 \sim 0.2$ & - \\
\cline { 2 - 6 } & $\mathrm{C}_{\mathrm{w}}$ & Air vertical turbulence coefficient & 0.01 & $0.01 \sim 0.1$ & - \\
\cline { 2 - 6 } & $\mathrm{K}_{\mathrm{x}}$ & Thermal horizontal mixing rate & 1 & $1 \sim 1.5$ & $\mathrm{~km}(\mathrm{~m} / \mathrm{s}) /{ }^{\circ} \mathrm{C}$ \\
\cline { 2 - 6 } & $\mathrm{K}_{\mathrm{z}}$ & Thermal vertical mixing rate & 1 & $1 \sim 1.5$ & $\mathrm{~km}(\mathrm{~m} / \mathrm{s}) /{ }^{\circ} \mathrm{C}$ \\
\cline { 2 - 6 } & $\mathrm{W}_{\mathrm{c}}$ & Plume-to-environment cutoff velocity & 0.5 & $0.2 \sim 0.8$ & $\mathrm{~m} / \mathrm{s}$ \\
\cline { 2 - 6 } & $\mathrm{W}^{*}$ & Air induced particle downdraft velocity & 0.01 & $0.01 \sim 0.02$ & $\mathrm{~m} / \mathrm{s}$ \\
\hline \multirow{5}{*}{} & $\mathrm{W}_{\mathrm{r}}$ & Large eddy reference vertical velocity & 1 & $1 \sim 1.5$ & $\mathrm{~m} / \mathrm{s}$ \\
\cline { 2 - 6 } & $\mathrm{W}_{0}$ & Initial plume vertical velocity & Computed & $5 \sim 15$ & $\mathrm{~m} / \mathrm{s}$ \\
\cline { 2 - 6 } & $D_{0}$ & Initial plume temperature anomaly & Computed & $5 \sim 15$ & ${ }^{\circ} \mathrm{C}$ \\
\cline { 2 - 6 } & $\mathrm{D}_{\mathrm{f}}$ & Effective diameter of flaming area & Computed & $-25 \sim 25 \%$ & $\mathrm{~m}$ \\
\cline { 2 - 6 } & $\mathrm{N}_{\mathrm{c}}$ & Number of updraft core & 1 & $1 \sim 20$ & $(-)$ \\
\cline { 2 - 6 } & $\mathrm{T}_{\mathrm{z}}$ & Atmospheric thermal lapse rate & Observed & $-25 \sim 25 \%$ & ${ }^{\circ} \mathrm{C} / \mathrm{km}$ \\
\hline & $\mathrm{V}$ & Average wind speed & Observed & $-25 \sim 25 \%$ & $\mathrm{~s}$ \\
\hline
\end{tabular}

The FAST analysis was introduced by [30] as a method to vary input variables simultaneously through their ranges of possible values following their given probability density functions (i.e., values which have a greater probability are chosen more often). All input parameters are assumed to be mutually independent and each is assigned a different frequency, which determines the number of times that the entire range of values is traversed. With each input parameter oscillating at a different characteristic frequency, a different set of input parameter values is obtained for each model run with every value used once. The mean and variance, which characterize the uncertainty due to the variability of the input parameters, are calculated for model output parameters. Fourier analysis of each output for all model runs is used to separate the response of the model to the oscillation of particular input parameters. Summation of those Fourier coefficients corresponding to a particular input parameter frequency and its harmonics determines the contribution of that input parameter to the model output variances. Finally, by scaling the relative contribution of the input parameters to the total variance, partial variances are obtained, which show the sensitivity of model output parameters to the variation of individual input parameters in terms of a percentage of the variance. The Fourier coefficients corresponding to input parameter frequencies and their harmonics do not account for the entire variance of the model outputs. The Fourier coefficients corresponding to linear combinations of more than one input parameter frequency account for the remaining fraction of the variance, which can be attributed to the combined influences of two or more parameters.

Details of the FAST analysis for a prescribed burn can be found in [10]. FAST results are shown in Figure 5. The ratio of partial variance of a parameter to total variance varies from one hour to another throughout the simulation period, but it only slightly affects the relative importance of this parameter 
to others. The results for two hours are shown to indicate this variation. The 15 parameters can be divided into three categories in terms of their importance. The first category includes the two most important parameters: the plume entrainment coefficient and number of plume updraft cores. Their ratios are about 35 and $26 \%$, respectively, at 1400 , and 35 and $32 \%$ at 1500 . In other words, each parameter contributes one fourth to one third to the total variance. The second category includes three important parameters: the initial plume temperature anomaly, diameter of flaming area, and thermal stability. Their ratios are about $10 \%$ at 1400 and vary between 6 and $12 \%$ at 1500 . Thus, each contribute about one tenth to total variance on average. The third category includes the remaining parameters, whose ratios are $1 \%$ or less. These parameters are not important to Daysmoke plume rise simulation.

The outcome of the FAST analysis was a redesign of Daysmoke with unimportant coefficients either pre-assigned or expressed in terms of other variables. The result is the reduced number of coefficients shown in Table 1.

Figure 5. FAST sensitivity analysis of Daysmoke. The horizontal coordinate lists the model parameters (see Table 1 for their meanings). The vertical coordinate is the ratio (\%) of partial variance of the parameter to total variance.

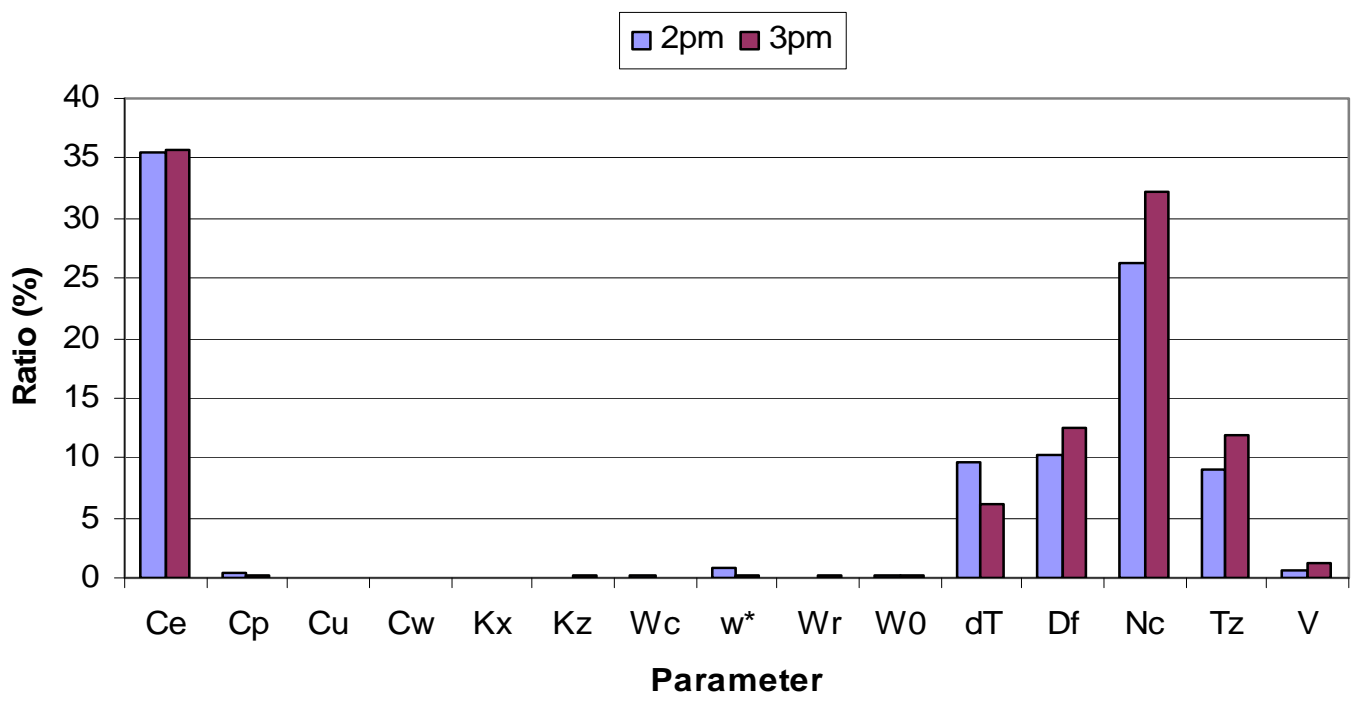

\subsection{Input Data}

Initial and hourly weather data include vertical profiles of temperature, three-dimensional components of the wind, and moisture (mixing ratio) for a location representative of the meteorology in the vicinity of the prescribed burn.

As regards initial values for the plume $-D_{0}, w_{0}$, and $\Delta T_{0}$ fire activity data include fuel type/amount (currently determined by National Fire Danger Rating Sytem Fuel Model [31] the area burned, the location of the burn and the date/start time of the burn. In addition the Each firing technique: backing fire, strip-head fires, head fire, ring fire and aerial ignition [32] produces fires of differing intensity and spread rates.

The process of converting from this description of a prescribed burn to the required Daysmoke inputs proceeds in four basic steps: fuel consumption calculation, total emissions calculation, hourly emissions and determination of $D_{0}$. The first three components are similar to those of the BlueSky 
Smoke Modeling Framework [33]. Total fuel consumption for each burn is determined using the single parameter regression equations for version 2.1 of CONSUME as given in appendix C of the User's Guide [34]. For each burn, total emissions for a number of chemical species are then calculated by multiplying the total consumed fuel by a species-specific emissions factor (Table 3). Values for the emissions factors are taken from the average emission factors of 26 intensively studied southeastern prescribed burns during 1995 and 1996 [35].

Hourly emissions are derived from this total value using the Emissions Production Model (EPM) [36] that derives time series of emissions and heat release for a fire based on a fairly simple source strength model. The time scale for completion of the flaming component is determined by the theoretical fire behavior. For a given wind speed, head/flanking/back fire spread rates are determined from BehavePlus [37] for the appropriate NFDRS fuel model.

Table 3. Average emission factors from 26 southeastern prescribed fires.

\begin{tabular}{ccc}
\hline Chemical Species & \multicolumn{2}{c}{ Emission Factor (g/kg) } \\
\cline { 2 - 3 } & Flaming Combustion & Smoldering Combustion \\
\hline $\mathrm{CO}_{2}$ & 1664.00 & 1649.00 \\
$\mathrm{CO}$ & 82.00 & 106.00 \\
$\mathrm{CH}_{4}$ & 2.32 & 3.42 \\
$\mathrm{C}_{2} \mathrm{H}_{4}$ & 1.30 & 1.30 \\
$\mathrm{C}_{2} \mathrm{H}_{2}$ & 0.50 & 0.48 \\
$\mathrm{C}_{2} \mathrm{H}_{6}$ & 0.32 & 0.46 \\
$\mathrm{C}_{3} \mathrm{H}_{6}$ & 0.51 & 0.59 \\
$\mathrm{C}_{3} \mathrm{H}_{8}$ & 0.09 & 0.11 \\
$\mathrm{C}_{3} \mathrm{H}_{4}$ & 0.05 & 0.05 \\
$\mathrm{NMHC}$ & 2.77 & 3.00 \\
$\mathrm{PM}_{2.5}$ & 11.51 & 10.45 \\
\hline
\end{tabular}

The heat release rate $(Q)$ is simply estimated as $50 \%$ of the product of the mass of fuel consumed per hour and the heat of combustion $\left(1.85 \times 10^{7} \mathrm{~J} \mathrm{~kg}^{-1}\right)$ [38]. The assumed $50 \%$ reduction in the heat release rate is designed to restrict only a portion of the total heat released going into the plume with the other $50 \%$ going into the heating of surrounding vegetation and ground surface. The initial values for the plume $-D_{0}, w_{0}$, and $\Delta T_{0}$ can be related to the heat of the fire [39] by

$$
w_{0} D_{0}^{2}=\frac{4 Q}{\pi C_{p} \rho \Delta T_{0}}
$$

$C_{p}$ is the specific heat $\left(\mathrm{J} \mathrm{kg}^{-1} \mathrm{~K}^{-1}\right), w_{0}$ is the vertical velocity entering the plume $\left(\mathrm{m} \mathrm{s}^{-1}\right), \rho$ is the air density $\left(\mathrm{kg} \mathrm{m}^{-3}\right)$ and $\Delta T_{0}$ is the temperature difference between the plume air and ambient conditions. Representative values for $w_{0}$ and $\Delta T_{0}$ of $25 \mathrm{~m} \mathrm{~s}^{-1}$ and $40{ }^{\circ} \mathrm{C}$ can be assumed based on numerical simulations of coupled fire atmosphere models [39]. Using these assumed values for vertical velocity and temperature difference allows $D_{0}$ to be determined.

Equation (15) with the above specified initial conditions is assumed to be valid at some reference height $h_{0}$ defined as the base of the plume where flaming gasses and ambient air have been thoroughly mixed and where the incipient plume temperature $\Delta T_{0}$ of $40{ }^{\circ} \mathrm{C}$ is found. For small prescribed burns, 
$h_{0}$ may be found approximately $10 \mathrm{~m}$ above ground and for wildfires, $h_{0}$ may be found several 100 's of meters above ground. For a typical grassfire [40] $h_{0}$ can be found near $35 \mathrm{~m}$.

The number of particles released per time step is determined from hourly emissions derived from the total fuel consumption [34] using the Emissions Production Model (EPM) of [36] modified for prescribed burns.

\subsection{Comparison with Briggs and LES Model Plumes}

Reference [41] used a high-resolution large eddy simulation (LES) model to explore the dynamics of buoyant plumes arising from a heat source representative of wildland fires. The model was designed to resolve the majority of the turbulent eddies in the plume and its environment, and thus does not suffer from approximations inherent in simple empirical plume models. Referenced [42] compared mean plume trajectories from the LES model with the two-thirds law plume rise model of [28] and its modification by [43] to account for finite-area sources. They found that within the first kilometer downwind from the heat source the mean plume rise seen in the simulations was well-described by the power law trajectory and is in reasonably good agreement with simple plume rise calculations. The LES and Briggs results place narrow bounds on mean plume trajectories and therefore provide a critical validation test for Daysmoke.

A version of the Briggs formulation provided by [44], and modified by [45] allows for insertion of the initial values used for Daysmoke.

$$
\begin{aligned}
& h=\left(\frac{3}{2 e^{2}}\right)^{1 / 3} F^{1 / 3} x^{2 / 3} / U \\
& \text { where } \\
& F=\frac{g \Delta T_{0} w_{0}{ }^{2} D_{0}^{2}}{4\left(T_{e}+\Delta T_{0}\right)}
\end{aligned}
$$

Here,

$x=$ the horizontal distance along the plume centerline downwind from the stack.

$U=$ the mean horizontal wind speed $\left(\mathrm{ms}^{-1}\right)$ for the air layer containing the plume.

$\Delta T_{0}=$ the plume temperature $(\mathrm{K})$ anomaly.

$w_{0}=$ the stack gas ejection speed $\left(\mathrm{ms}^{-1}\right)$.

$D_{0}=$ the internal exit diameter (m) of the stack.

$H=$ the height of the plume axis above the source (stack) (m).

$e=$ the entrainment coefficient (conventionally, 0.66) for the Briggs model.

$g=$ gravitational acceleration $\left(\mathrm{ms}^{-2}\right)$.

$T_{e}=$ plume exit temperature $(\mathrm{K})$.

Daysmoke was run with a test profile of temperature and wind created from a WRF generated sounding for Ft. Benning, GA, for 23 January 2009. All winds below $1700 \mathrm{~m}$ were set to blow from the west with a speed of $U=9.0 \mathrm{~ms}^{-1}$ as the Briggs theory is set for a layer mean wind speed. The outcome of the comparison for the first seven kilometers downwind is shown in Figure 6. Plume boundaries calculated via Equation (5) are shown by the white lines. The green lines identify mean plume trajectories from the Briggs two-thirds law for a neutral atmosphere. For the initial effective 
plume diameter $D_{0}=62 \mathrm{~m}$ (Figure 6a), the Daysmoke plume, driven by the hyperbolic vertical velocity profile (alternating dark and light green lines at the left side of the figure), rose more steeply during the first $500 \mathrm{~m}$ downwind. Then the centerline for the Daysmoke plume declined from $60 \mathrm{~m}$ above the Briggs trajectory at $500 \mathrm{~m}$ downwind to intersecting the Briggs trajectory at $3.2 \mathrm{~km}$ downwind. The outcome was a more highly bent-over plume. Beyond $3.2 \mathrm{~km}$, the Daysmoke centerline ran slightly below the Briggs trajectory-15 $\mathrm{m}$ below where the centerlines crossed the mixing height (dashed line) at $7.3 \mathrm{~km}$ downwind from the ignition site.

Figure 6. Daysmoke-simulated plume boundaries (white lines), Daysmoke plume centerline (red lines), and Briggs-calculated mean plume trajectories (green lines) for (a) $D_{0}=62 \mathrm{~m}$; and (b) $D_{0}=17 \mathrm{~m}$. The mixing height is given by the dashed line.
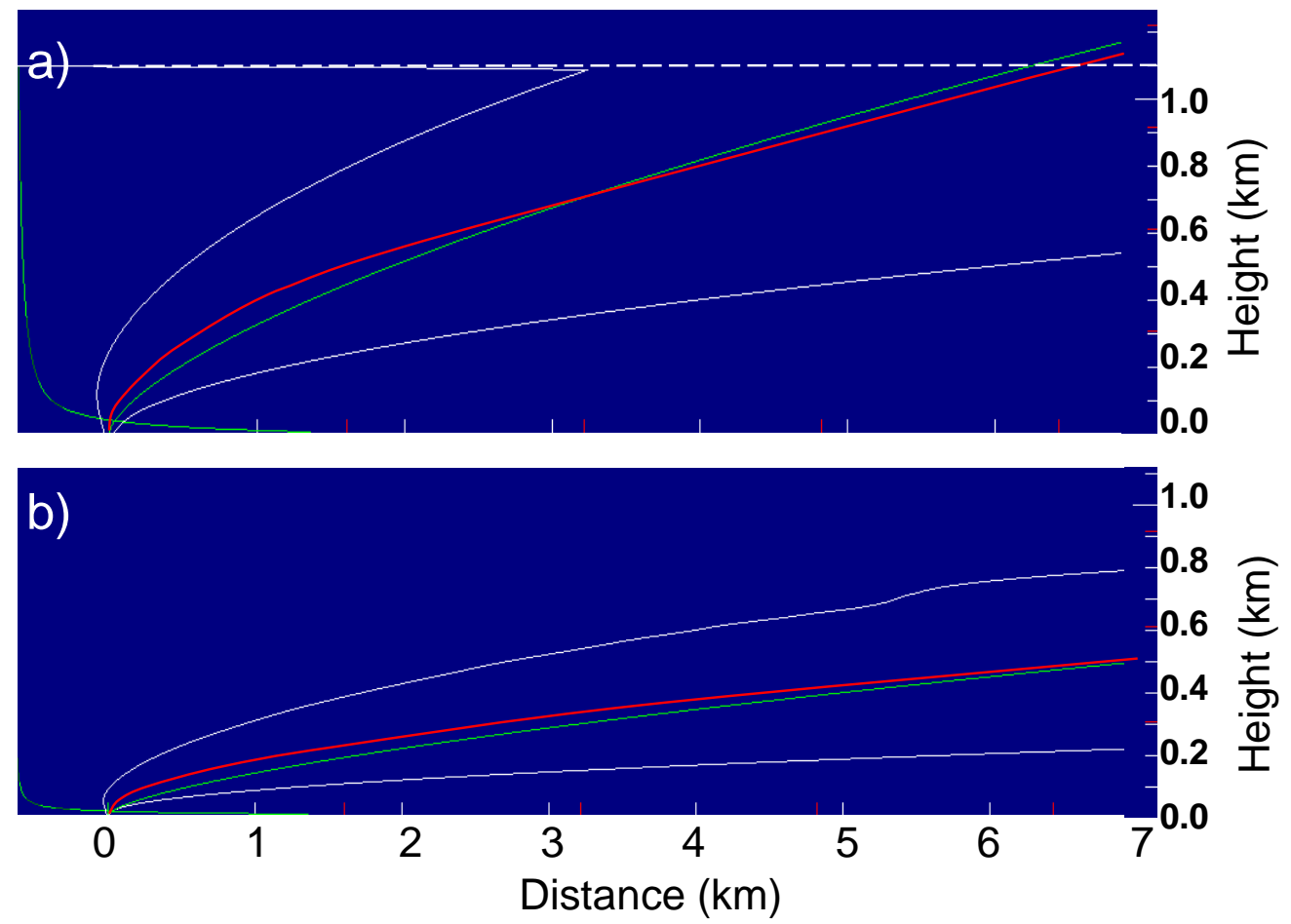

Similar results were found for the smaller $D_{0}=17.0 \mathrm{~m}$ plume (Figure $6 \mathrm{~b}$ ). This Daysmoke plume initially rose more steeply than the Briggs trajectory for the first $150 \mathrm{~m}$ downwind placing the plume approximately $25 \mathrm{~m}$ above the Briggs trajectory. Then the two curves gradually converged past $7.5 \mathrm{~km}$ downwind.

It is apparent that the Daysmoke plumes are initially more vigorous but, overall, the plume rise is well-explained by the power-law trajectory. The differences are minimal in comparison with the area swept out by the plume boundaries.

\section{Model Evaluation (Study of Weak Plumes)}

During 2008-2009, a smoke project was conducted at Fort Benning, GA. The site was chosen because of the large size of its prescribed burn operation and the aggressiveness of its burn program - typically a 1-3 year fire return interval. Burning when fuel loadings had increased to just carry fire would not be expected to release heat sufficient to loft a towering plume. Daysmoke 
simulations produced some plumes that ascended to the mixing height. Other simulated plumes rose partway through the mixing layer before losing identity as a plume-breaking up and being redistributed by convective circulations.

The project collected data on plume top height and ground-level $\mathrm{PM}_{2.5}$ - both critical data sets for validation of Daysmoke - for eleven burns. Three mobile trucks, each equipped with pairs of DustTrak real-time $\mathrm{PM}_{2.5}$ samplers [46], were operated at distances of roughly 1 mile, 2 miles, and 4 miles downwind from the burn. The trucks were moved when wind shifts created the necessity to relocate beneath the smoke plumes. An example of the truck protocol is shown in Figure 7. The three trucks (color coded) were moved to various positions during the burn to maintain location under the plume (shown schematically by the parabolic boundaries) as judged by the truck crews. $\mathrm{PM}_{2.5}$ observations by the DustTrak samplers were corrected for wood smoke by multiplying by a factor of 0.275 .

Figure 7. Positions of three trucks: Truck 1 (blue), Truck 2 (yellow), and Truck 3 (red) during the 9 April 2008 prescribed burn at Fort Benning. Grid outlines one mile squares.

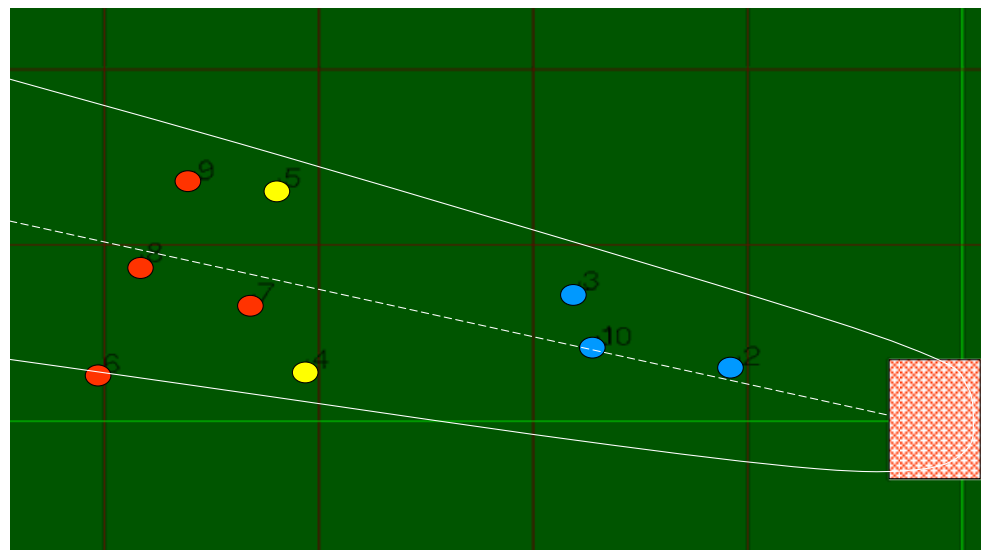

Daysmoke was run with hourly vertical profiles of wind, humidity, and temperature from high-resolution weather simulations by the WRF model. Emissions data were provided by the methodology described in c) Input Data above.

Our analysis placed the eleven burns in five categories (Table 4). The first column shows that three burns fell into the first category-ground-level smoke concentrations increased with distance from the burn. Plume statistics are summarized in Figure 8. Daysmoke contains stochastic terms for convective circulations that are set so they cannot be repeated. Thus successive Daysmoke runs will give slightly different answers. To smooth out the effects of the stochastic terms, we constructed ensemble averages of five simulations. The averages of the residuals (defined as the differences between ensemble averages and observed $\mathrm{PM}_{2.5}$ ) for the periods of the burns (defined as time of ignition until completion of ignition) for the three days are shown by the squares in Figure 8 . The spreads of residuals are given by the horizontal bars connected by the vertical lines. Average residuals for all three trucks ranged less than $\pm 5{\mu \mathrm{gm}^{-3}}^{-}$. The magnitudes of the spreads for Truck1 and Truck 2 never exceeded $10 \mu \mathrm{gm}^{-3}$. Given uncertainties in defining updraft core number and model errors in wind speed and direction, the results for the first category of Table 4 are as good as can be expected from an empirical-statistical modellike Daysmoke. 
Table 4. Fort Benning burns listed by plume characteristics.

\begin{tabular}{ccccc}
\hline Increase & Decrease & Extreme Decrease & Out of Plume & Misc \\
\hline 3 & 3 & 2 & 2 & 1 \\
9 April 08 & 14 April 08 & 15 January 09 & 13 January 09 & 14 January 09 \\
21 January 09 & 15 April 08 & 23 January 09 & 20 January 09 & \\
8 April 09 & & & & \\
\hline
\end{tabular}

Figure 8. Ensemble average Daysmoke minus observed $\mathrm{PM}_{2.5}$ (squares) at the three trucks for the three days when smoke concentrations increased with distance. The spreads of the departures are shown by the horizontal bars.

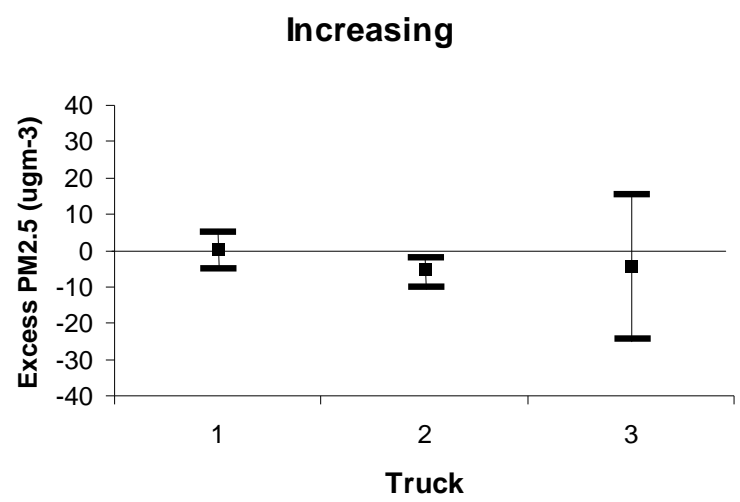

The results for the second category of Table 4-ground-level smoke concentrations decreased with distance from the burn - are shown in Figure 9. Daysmoke slightly under-predicted smoke at Truck 1 and over-predicted smoke at Truck 2 and Truck 3. The discrepancies are small-less than $10 \mu \mathrm{gm}^{-3}$. Spreads also were small at all three trucks; the larges being $21 \mathrm{gmm}^{-3}$.

Figure 9. Ensemble average Daysmoke minus observed $\mathrm{PM}_{2.5}$ (squares) at the three trucks for the three days when smoke concentrations decreased with distance. The spreads of the departures are shown by the horizontal bars.

Decreasing

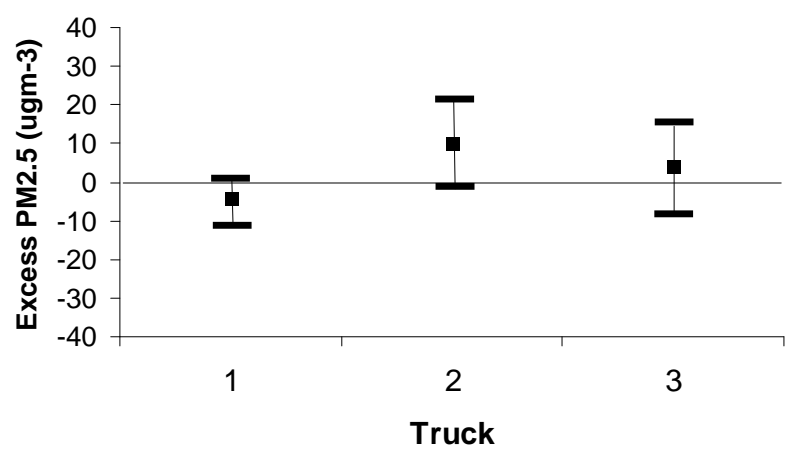

The third column of Table 4 lists the two days with plumes characterized by very high concentrations of smoke at Truck 1 and very steep gradients of smoke concentration between the trucks (Figure 10). Daysmoke greatly under-predicted burn event smoke at Truck $1-$ minus $60 \mu \mathrm{gm}^{-3}$ with a spread ranging from -32 to $-89 \mu \mathrm{gm}^{-3}$. The average residual was improved for Truck $2\left(-12 \mu \mathrm{gm}^{-3}\right)$ but the 
spread remained high ( -47 to $22 \mu \mathrm{gm}^{-3}$ ). The better results at Truck 3 could be explained by the truck being located near the edges of the plumes.

Figure 10. Ensemble average Daysmoke minus observed $\mathrm{PM}_{2.5}$ (black squares) at the three trucks for the two days of high smoke concentrations at Truck 1 and steep gradients of smoke between the trucks. The spreads of the departures are shown by the horizontal bars. Red bars: Daysmoke minus observed $\mathrm{PM}_{2.5}$ for a highly tilted plume for 23 January 2009.

\section{Extreme Decrease}

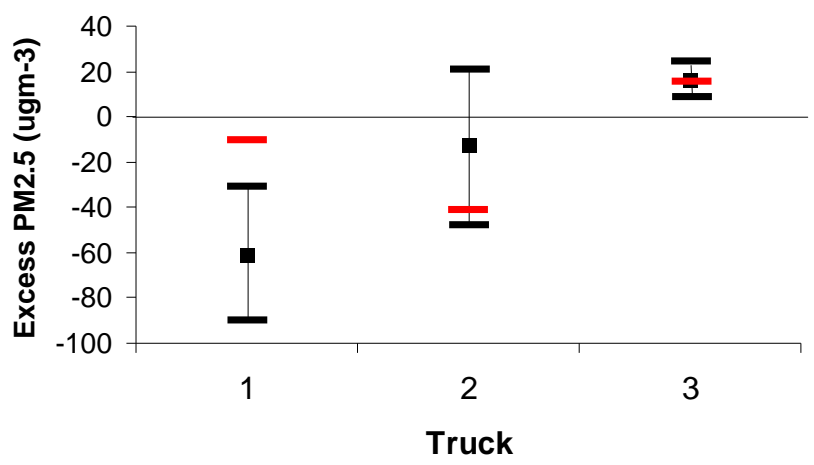

The fourth and fifth columns of Table 4 list those days characterized by, respectively, truck locations away from the plume (either no roads or movement restricted by military activities) and corrupted or lost data.

The poor results from Daysmoke for the events characterized by high smoke concentrations at Truck 1 and steep gradients of $\mathrm{PM}_{2.5}$ between the trucks (column 3 of Table 4) needs further explanation. That these two events were extraordinary is shown by peak $30-\mathrm{s} \mathrm{PM}_{2.5}$ for the seven days for which complete data are available for all three trucks (Figure 11). Peak $\mathrm{PM}_{2.5}$ exceeding $600 \mu \mathrm{gmm}^{-3}$ for 15 January and 23 January 2009 imply that Truck 1 was located within the ascending plume on both days while Truck 2 and Truck 3 were located within particulate matter detrained from the plume as it passed overhead. This implication contrasts with Daysmoke solutions for the other days that placed the trucks either within detrained smoke or within remnants of the smoke plume torn apart and down-mixed by convective circulations.

Given the initial conditions of $w_{0}=25 \mathrm{~m} \mathrm{~s}^{-1}$ and $\Delta T_{0}=40{ }^{\circ} \mathrm{C}$, no choice for updraft core number could produce both the very high smoke concentrations at Truck 1 nor the steep gradients of $\mathrm{PM}_{2.5}$ between the other trucks. Therefore the Daysmoke bent-over plume solution failed to reproduce the events of 15 January and 23 January 2009.

We varied the initial conditions subject to the constraint that the flux, given by the product of the initial velocity with the square of the initial effective plume diameter, was held constant. The top panel of Figure 12 shows the bent-over solution for a 1-core updraft plume for 23 January 2009. We reduced the initial conditions to $w_{0}=0.5 \mathrm{~ms}^{-1}$ and $\Delta T_{0}=1.0{ }^{\circ} \mathrm{C}$ to obtain the solution for a "highly tilted" plume (middle panel of Figure 12). Conservation of total flux required increasing the initial effective plume diameter from $59 \mathrm{~m}$ to $417 \mathrm{~m}$ - a requirement that decreases the impact of entrainment on the plume. Thus the weakly buoyant highly-tilted plume was driven almost entirely by buoyancy and was capable of growth through the depth of the mixing layer. 
Figure 11. Peak 30-s averaged $\mathrm{PM}_{2.5}$ for seven complete data sets from the 2008-2009 smoke project at Fort Benning, GA. The burn dates are: (1) 9 April 2008; (2) 14 April 2008; (3) 15 January 2009; (4) 21 January 2009; (5) 23 January 2009; (6) 8 April 2009; and (7) 9 April 2009.

\section{Peak 30-sec Average PM2.5}

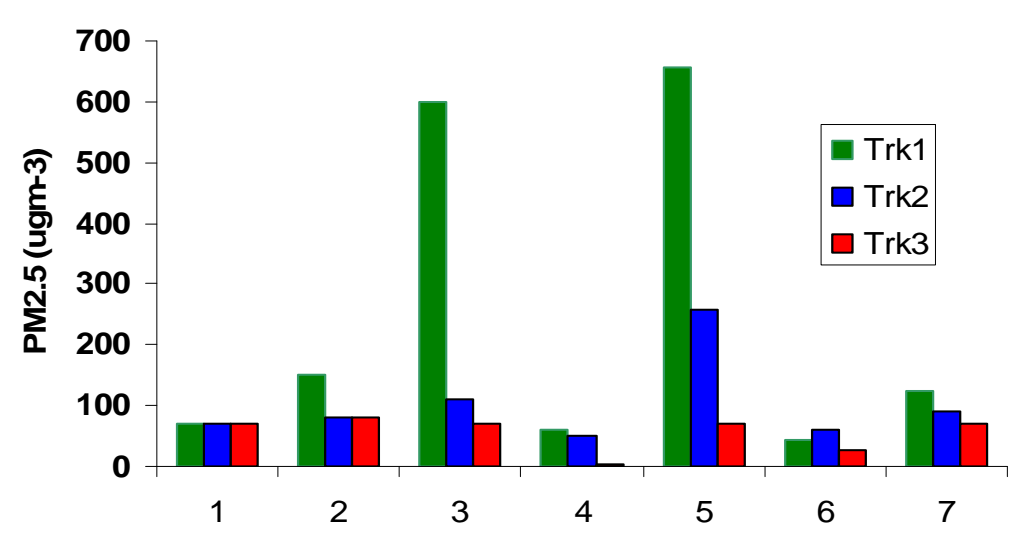

Figure 12. Daysmoke plumes for three selections of initial conditions. The horizontal white line gives the mixing height.

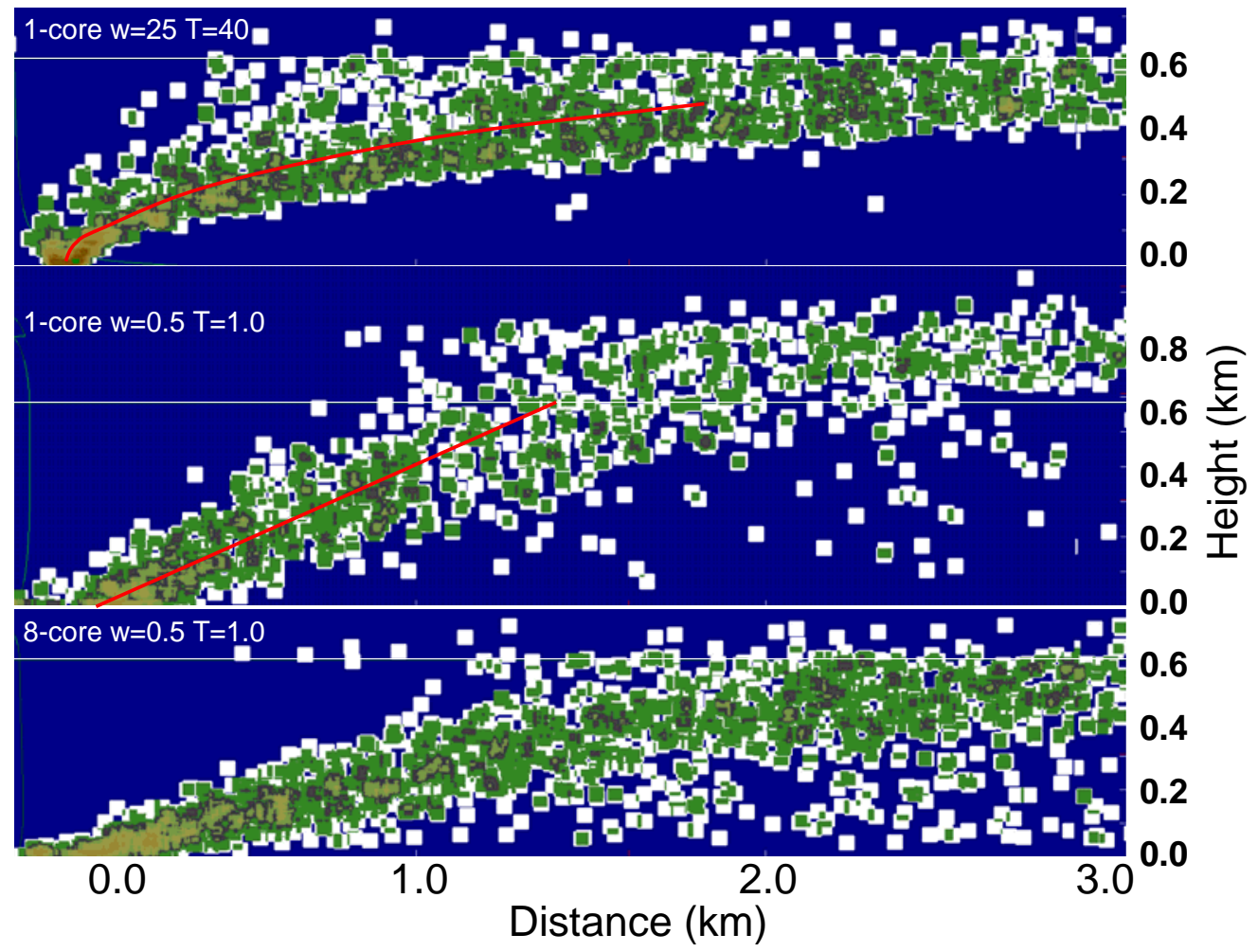

The plume axis is characteristically quasi-linear as compared with the parabolic axis of the bent-over plume (upper panel). Running Daysmoke with the updraft core number set to eight (estimated for this burn) yielded the highly tilted plume solution shown in the lower panel of Figure 12 Note how this plume runs along the ground before ascending. The plume tilt of 15 degrees is greater than that for the 1-core plume (middle panel) and the plume is confined to the mixing layer. The red 
bars in Figure 10 show that the 30-min averaged $\mathrm{PM}_{2.5}$ difference between Daysmoke and observed smoke concentration at Truck 1 of $-8 \mu \mathrm{gm}^{-3}$ was greatly improved over the $-89 \mu \mathrm{gm}^{-3}$ calculated for the bent-over plume. Results for Truck 2 and Truck 3 showed minor changes from the original differences for 23 January 2009.

Is the highly-tilted plume represented by Briggs theory? Figure 13 shows plume boundaries (white lines) for the 1-core updraft 23 January 2009 simulation (aspect ratio: $\Delta x / \Delta z=2$ ). The plume axis (red line) describes a plume that runs along the ground for approximately $0.6 \mathrm{~km}$ then rises at approximate $3.5 \mathrm{~ms}^{-1}$ (dark green/light green line) along a quasi-linear axis. The weak buoyancy of the plume, shielded from entrainment by its $417 \mathrm{~m}$ diameter, ascended to the mixing height $2 \mathrm{~km}$ downwind and rose $100 \mathrm{~m}$ above the mixing layer (light blue line). The Briggs solution (Equation 16), shown by the green line, has the plume ascending to $250 \mathrm{~m} 4 \mathrm{~km}$ downwind from the burn.

Figure 13. Plume boundaries (white lines) for the highly-tilted plume simulated by Daysmoke for the 23 January 2009 prescribed burn. Other lines are: plume axis (red), the Briggs solution (green), the mixing height (light blue), and the plume vertical velocity (alternating dark green/light green).

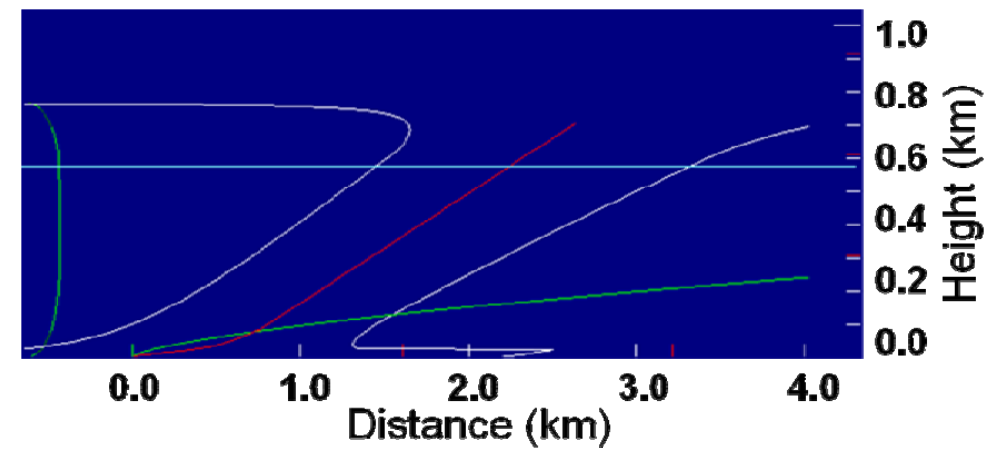

Is there independent evidence to support the Daysmoke solution for the highly-tilted plume? Figure 13 shows stack and cooling tower plumes from an electric power generating station. The stack plume shows the strongly bent-over parabolic structure (red line) typical of relative high velocity effluents rapidly slowed by entrainment on ejection through a relatively small plume diameter. The cooling tower plume, tilted along a linear axis (blue line), is characteristic of low velocity effluents ejected within a relative large plume diameter and driven by buoyancy. The plume structures modeled with Daysmoke compare favorably with the plumes shown in Figure 14.

Plume top heights (squares) and height ranges (connecting lines) for plumes simulated by Daysmoke (red squares in Figure 15) compare favorably with plume top heights measured by ceilometer (black squares). Relative to the observed lower range, Daysmoke plume tops were on the average $8 \mathrm{~m}$ high. However, relative to the observed higher range, Daysmoke tops were on the average $-200 \mathrm{~m}$ low. Thus Daysmoke plume tops were, overall, slightly low. 
Figure 14. Plumes from an electrical power generating station.

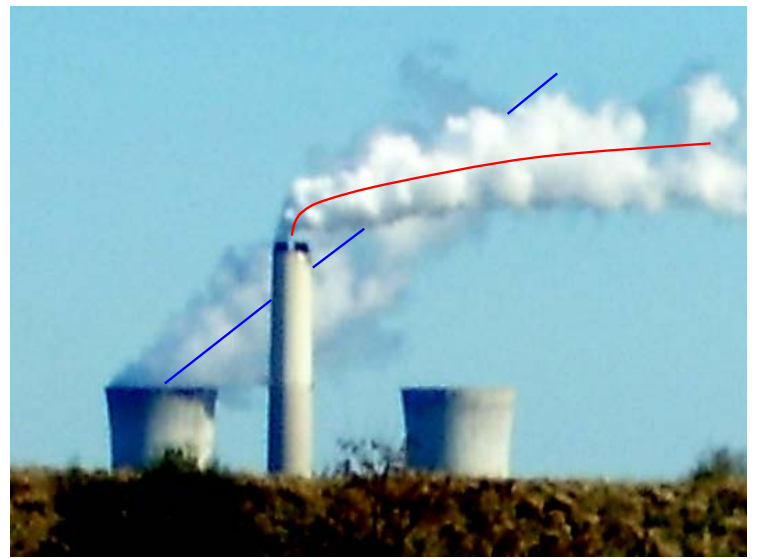

Figure 15. Plume heights for Daysmoke-simulated plumes (red squares) compared with plume heights observed by ceilometer (black squares) for six prescribed burns at Fort Benning.

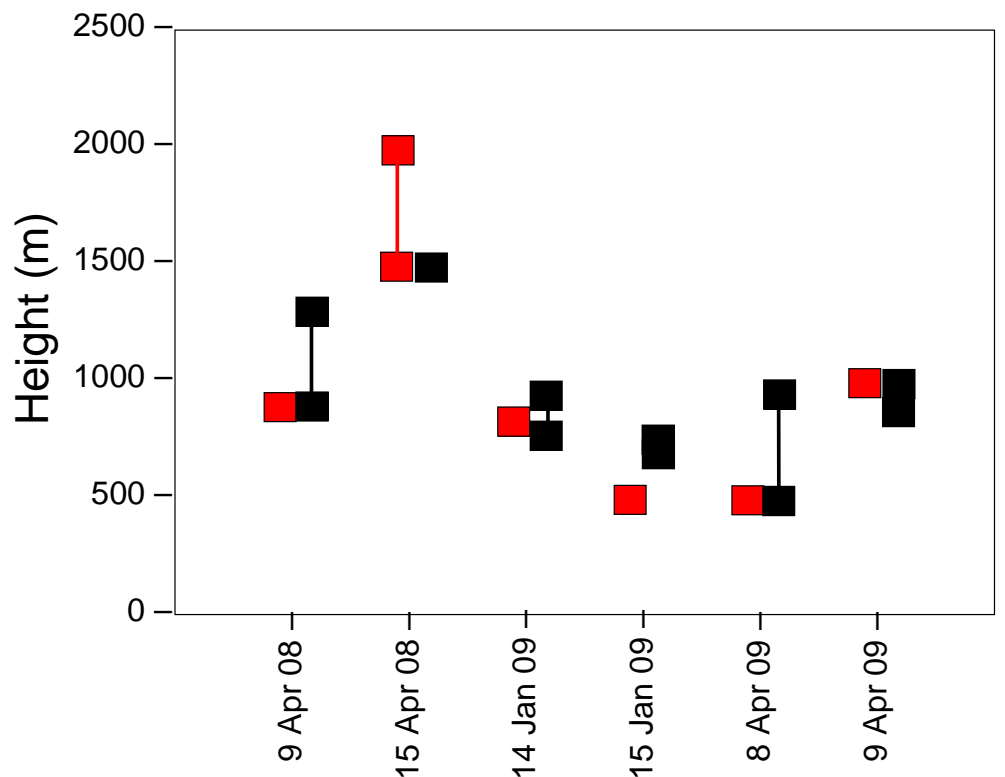

\section{Model Application (CMAQ)}

An adaptive grid version of CMAQ (AG-CMAQ) has been recently developed to better resolve the processes involving plumes [20] AG-CMAQ integrates the adaptive grid algorithm of reference [47] into CMAQ version 4.5 and is based on the adaptive grid air pollution model described in [11,12]. AG-CMAQ employs r-refinement: the number of grid cells remains constant but grid nodes are moved to cluster in areas where plumes are detected. Although the nodes are relocated, their connectivity does not change and the structure of the grid is maintained. In AG-CMAQ, a curvilinear coordinate system is fitted to the adapted non-uniform grid and, using coordinate transformations, the governing equations are transformed to a space where the grid is uniform. Then the transformed equations are solved in this space by directly applying the CMAQ solution algorithms that are designed for uniform grids. A variable time-step algorithm [48] allows each cell in AG-CMAQ to be assigned a unique local time-step and was included in the model to improve computational efficiency. 
The objective of grid adaptation in AG-CMAQ is to achieve more accurate representations of spatial fields by increasing grid resolution at locations where the error in numerical solutions is largest. The adaptation is achieved by estimating a weight function that efficiently quantifies numerical error and clustering grid nodes within the regions that result in the highest weights. The initial application of AG-CMAQ attempted to model biomass burning plumes impacting air quality in the Atlanta metropolitan area [20]. For that simulation, the Laplacian of the concentration of primary particulate matter from biomass burning was used as a weight function. Comparison of AG-CMAQ's performance to that of the static grid CMAQ model indicated that grid adaptation resulted in reduced numerical diffusion, better defined plumes, and closer agreement with site measurements. Here, we describe an application of AG-CMAQ to model prescribed burn plumes at Fort Benning, GA using information provided by Daysmoke.

Daysmoke can be applied as an emissions injector for AG-CMAQ in the same manner as it has been previously used with CMAQ. Detailed information describing plume rise or vertical distribution of buoyant prescribed burn emissions is necessary to achieve realistic results with gridded photochemical models that typically lack the mechanisms necessary to simulate this process. The fire emissions are injected into CMAQ's vertical layers following the vertical pollutant profile produced by Daysmoke at a downwind distance that allows full plume development. The location at which the emissions are injected within the horizontal CMAQ domain is not a straightforward choice. Injecting the emissions at the fire emissions source implies that a vertical profile modeled downwind of the fire is applied further upwind at the location of initial release. On the other hand, injection of emissions downwind at the location where the plume's fully developed vertical profile was estimated with Daysmoke entails neglecting chemistry and aerosol processes included in CMAQ but absent from Daysmoke up to this downwind distance. The error from either choice is greater as the downwind distance necessary to achieve a fully developed vertical plume profile increases relative to grid resolution. Plumes that rapidly reach their maximum plume rise and vertically distribute pollutants may not bring forth significant errors. However, given that full plume development may occur at distances larger than $15 \mathrm{~km}$ and grid resolution in CMAQ has been previously taken down to $1 \mathrm{~km}$, this might not necessarily be the case. The significance of this issue is even greater in AG-CMAQ, where an initial increase in resolution around the source of emissions is meant to enhance chemical and physical processes shortly after release. In the future, a tighter coupling of Daysmoke with AG-CMAQ should address these issues.

In the following application we have modeled the effects on air quality from a prescribed burn at Fort Benning, GA on 9 April 2008. During this day, 300 acres of wildland were treated. Ignition occurred at 16:30 GMT and flaming continued until 18:45 GMT, with smoldering emissions continuing thereafter. This episode is of particular interest because peaking $\mathrm{PM}_{2.5}$ concentrations were recorded at the Columbus, GA airport air quality monitoring site, possibly due to the impact of the burn, providing an opportunity to compare modeled results to those observed at a regulatory network station.

Hourly emissions from the prescribed burn were estimated with the Fire Emission Production Simulator (FEPS) [49] using information provided by land managers at the site. Background emissions for the photochemical simulations were prepared using the Sparse Matrix Operator Kernel Emissions model (SMOKE, version 2.4) [50] with a 2002 "typical year" emissions inventory [51] projected to year 2008 using the existing control factors and the growth factors generated from the Economic Growth Analysis System (EGAS) Version 4.0. Meteorological data is provided through the Weather 
Research and Forecasting model (WRF, version 3.1) [52] at $1.333 \mathrm{~km}$ resolution and 34 vertical layers of increasing depth from the surface to the top. Initialization, boundary conditions constraining, and nudging at 6-hour intervals were performed using analysis products from the North American Mesoscale (NAM) model. The CMAQ domain covered $120 \times 124 \mathrm{~km}$ over southwestern Georgia and southeastern Alabama with a $1.333 \mathrm{~km}$ horizontal grid spacing and 34 vertical layers.

Daysmoke simulations were undertaken using 6-updraft cores. For fire emissions injection into CMAQ we used the vertical plume profile estimated by Daysmoke $4 \mathrm{~km}$ downwind of the fire, and applied it at the location of the fire in the CMAQ domain. This length provided sufficient time for full plume development and was not exceedingly distant from the source ( 3 grid cells downwind). The time it takes the plume to reach a downwind distance of $4 \mathrm{~km}(3 \times 1.33 \mathrm{~km}$ cells $)$ varies with altitude and time, but for the majority of emissions in this particular fire, it takes about 15 minutes. During this time, some particles are discharged from the plume through the cited mechanisms. With slower wind speeds more particles are detrained, fall out, or get removed by convective eddies to be dispersed throughout the mixing layer.

The vertical distribution of $\mathrm{PM}_{2.5}$ fire emissions for the entire episode is shown in Figure 16. Note that the lower layers are thinner than are the higher layers and the distribution is not normalized. The maximum vertical injection height of fire emissions is at about $1 \mathrm{~km}$ (the 10th layer of the model). The WRF-simulated hourly mixing heights at the burning location during the flaming period (1100-1400 LST) were 753, 979, 1213 and 1334 meters, respectively. An additional 24 vertical layers extended the top of the CMAQ model domain to near $18 \mathrm{~km}$.

The largest fraction of emissions is injected into layer 8, which spans an altitude from approximately $500 \mathrm{~m}$ to $680 \mathrm{~m}$ above the ground. Nearly $70 \%$ of fire emissions were distributed into layers 6,7 , and 8 which extend from approximately $335 \mathrm{~m}$ to $680 \mathrm{~m}$ above the ground. The same procedure was applied for fire emissions injection in the AG-CMAQ simulation. Grid adaptation was driven by the curvature in the fire emitted $\mathrm{PM}_{2.5}$ concentration field.

Figure 17 shows the time evolution of $\mathrm{PM}_{2.5}$ concentration at the Columbus Airport monitoring site $30 \mathrm{~km}$ from the location of the prescribed burn for both the CMAQ and AG-CMAQ runs, as well as available observational data. CMAQ overestimates the peak concentration while AG-CMAQ underestimates this value. However, the magnitude of the error in the maximum $\mathrm{PM}_{2.5}$ level for both models is approximately the same $\left(4 \mu^{-3} \mathrm{gm}^{-3}\right.$. A sharp increase in concentration is perceived in the observations after 21:00 UTC. Similarly, rapid increments are perceived in the CMAQ and AG-CMAQ simulations, although occurring at earlier times. The CMAQ-modeled $\mathrm{PM}_{2.5}$ concentrations fall abruptly after peaking, while the decrease is gentler with AG-CMAQ and more closely resembles that seen in the observations. Throughout the simulation, the mean fractional error in the modeled results relative to station observations was reduced by $17 \%$ on average using AG-CMAQ compared to CMAQ. A timing mismatch in observed and modeled peak pollutant levels is also evident. The fact that emissions estimated by FEPS are hourly starting at the top of the hour and ignition actually occurred 30 minutes past 16:00 GMT may at least partially account for the discrepancy. 
Figure 16. Vertical distribution of prescribed burn $\mathrm{PM}_{2.5}$ emissions into CMAQ and AG-CMAQ layers.

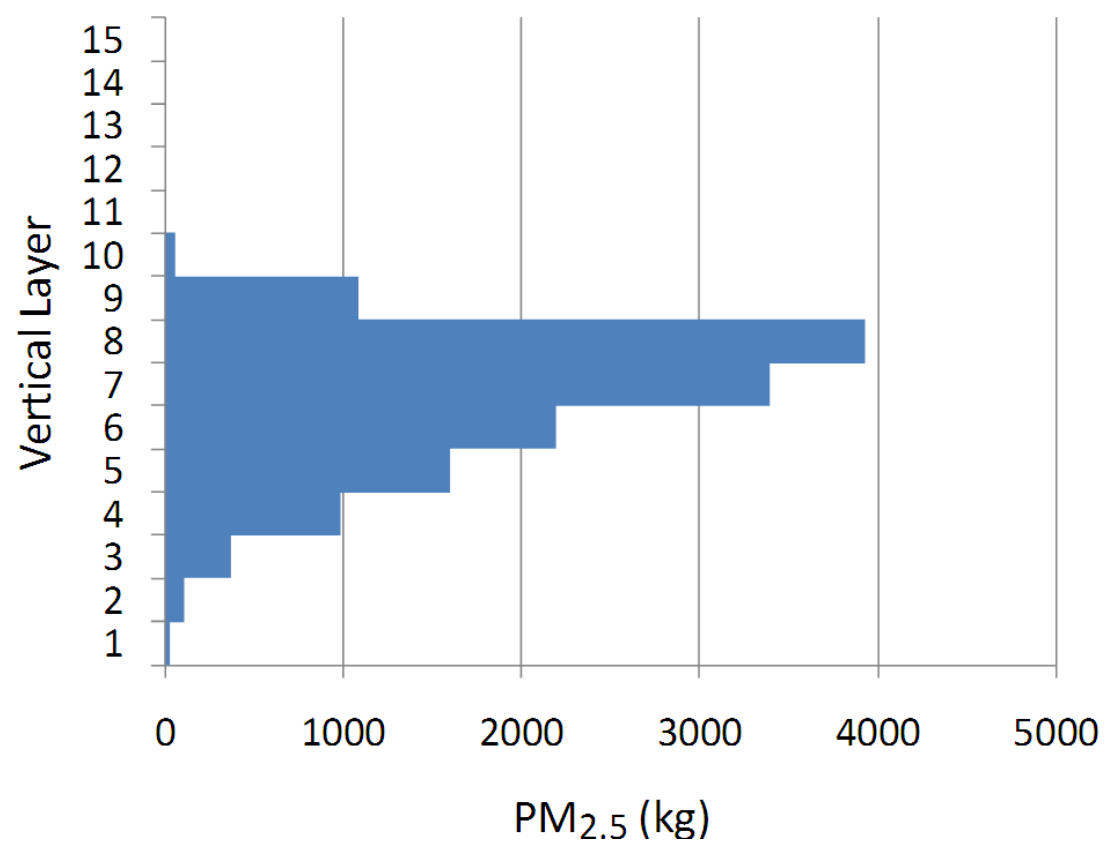

Figure 17. Hourly averaged $\mathrm{PM}_{2.5}$ concentrations $\left(\mu \mathrm{gm}^{-3}\right)$ as observed and modeled by CMAQ and AG-CMAQ at the Columbus airport air quality monitoring site on April 9, 2008.

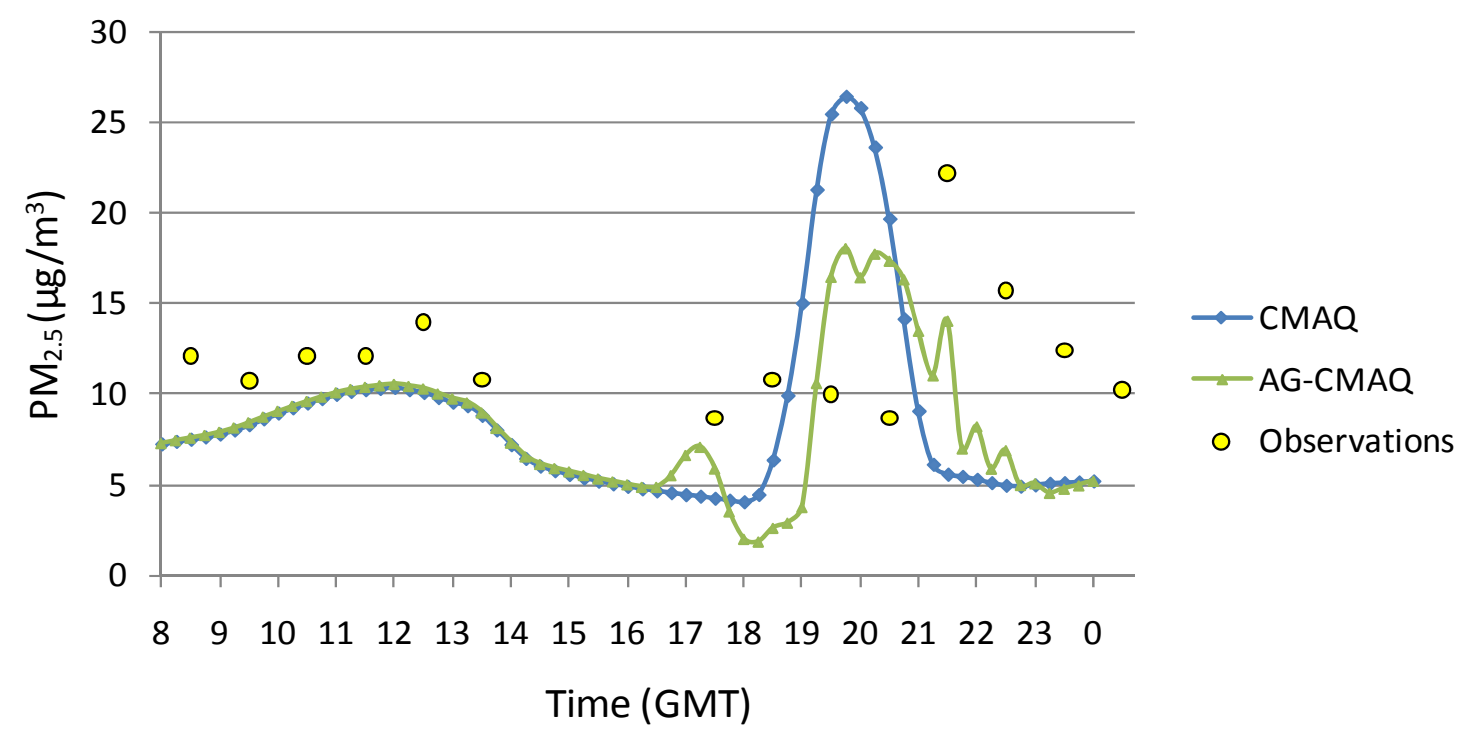

Better understanding of the modeled results can be gained from the pollutant concentration fields shown in Figure 18. These pollutant fields correspond to the instance of maximum concentration at the Columbus airport location. The static grid CMAQ plume appears more diffused, relative to that produced with AG-CMAQ. It is also apparent that impact at the airport site is not direct, but rather a tangential hit. The pollutant field from the AG-CMAQ simulation shows a more concentrated plume with higher pollutant levels near a core that has persisted longer into the simulation. Significant grid refinement occurs at the source of emissions as well as along the plume centerline. The area surrounding 
the airport site also experiences appreciable refinement throughout the run. Figure 19 further contrasts the plumes produced with CMAQ and AG-CMAQ. These three-dimensional $\mathrm{PM}_{2.5}$ concentration plots show surface level concentrations as well as a $3 \mathrm{D}$ plume volume defined as a constant concentration

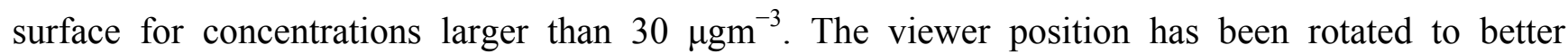
appreciate the plume volumes. From the images is it noticeable that the plume produced in the AG-CMAQ simulation offers a greater level of detail and is likely able to pick up finer details of the wind field to which it is subjected. The plume structures, undoubtedly, are highly dependent on the vertical pollutant distribution information provided by Daysmoke.

Figure 18. Simulated $\mathrm{PM}_{2.5}$ concentrations $\left(\mu \mathrm{gm}^{-3}\right)$ on April 9, 2008 at 19:45 GMT using (A) CMAQ; and (B) AG-CMAQ. Locations of the prescribed fire at Ft. Benning and the Columbus airport air quality monitoring site are indicated by red and white circles respectively.
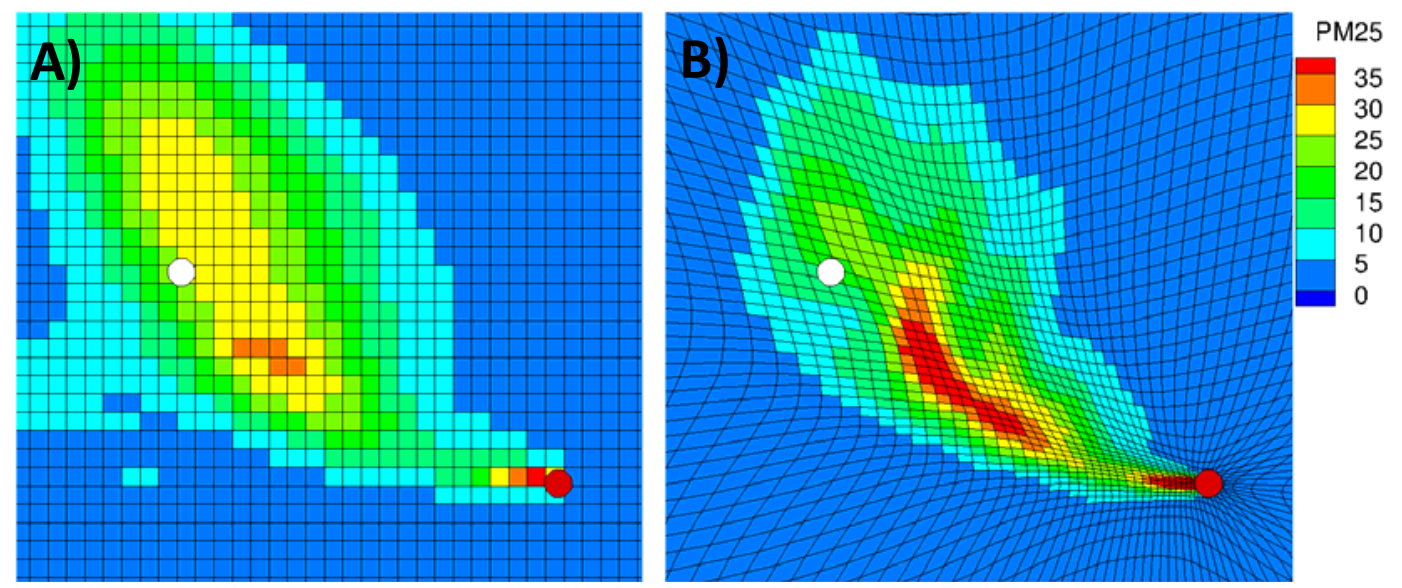

Figure 19. Three-dimensional views of $\mathrm{PM}_{2.5}$ concentrations $\left(\mu \mathrm{gm}^{-3}\right)$ on April 9, 2008 at 19:15 GMT using (A) CMAQ; and (B) AG-CMAQ.
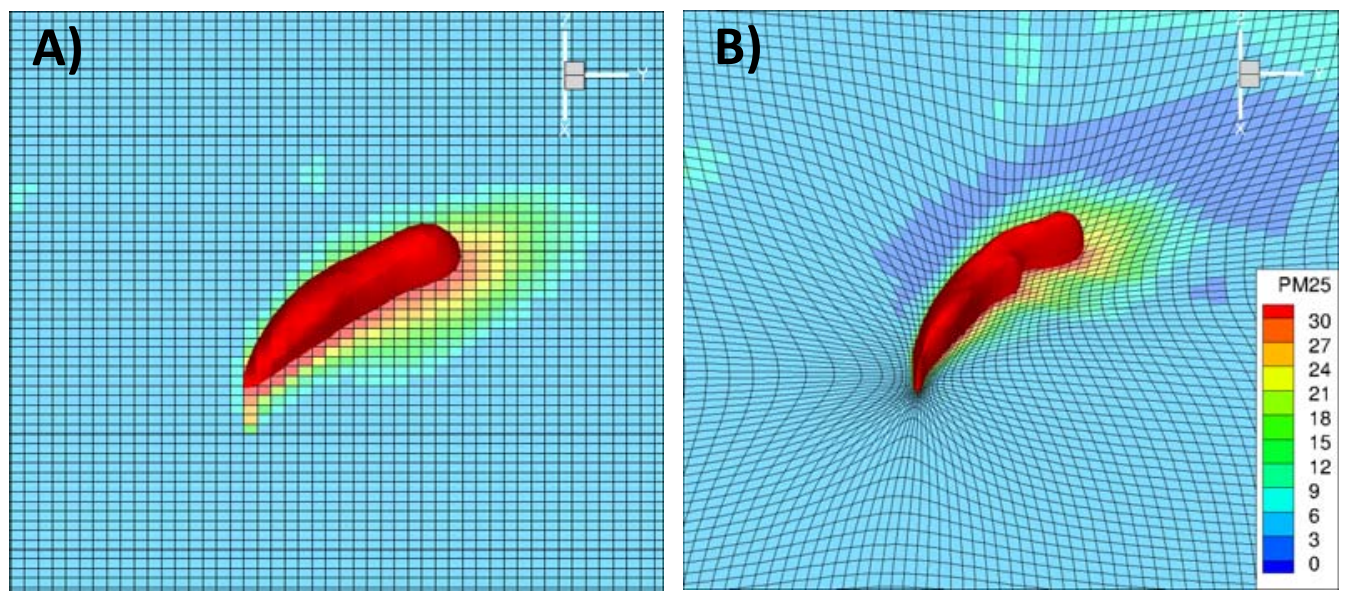

\section{Summary and Concluding Remarks}

In this paper we have presented the plume rise and dispersion model Daysmoke, intended for the simulation of smoke plumes from wildland fires. The model theory presented in this paper is the outcome of a former version that was subjected to a sensitivity analysis with the Fourier Amplitude Sensitivity Test (FAST). The FAST analysis identified empirical parameters important for plume 
height prediction. Therefore, many empirical coefficients have been pre-assigned or expressed in terms of other variables.

We compared Daysmoke plumes with Briggs theory and found good agreement for "bent-over" plumes although the two-thirds theory is not explicit in Daysmoke. However, the solutions for "highly-tilted" plumes characterized by weak buoyancy, low initial vertical velocity, and large initial plume diameter do not match Briggs theory.

We further evaluated Daysmoke by comparing simulations and observations of $\mathrm{PM}_{2.5}$ and plume height for weak plumes from eleven prescribed burns at Fort Benning, GA. Simulations of ground-level $\mathrm{PM}_{2.5}$ compared favorably with observations taken from three mobile trucks out to a distance of eight kilometers. Daysmoke plume tops were found near the lower end of the range of observed plume tops for six prescribed burns.

Daysmoke simulated vertical smoke profiles necessary for initializing the smoke concentrations in CMAQ (with and without adaptive grid). CMAQ simulation results show the detail and accuracy that can be obtained at the regional scale.

The initial plume vertical velocity of $25 \mathrm{~ms}^{-1}$ was assumed based on numerical simulations of coupled fire-atmosphere models [39] The vertical velocity was claimed to be an average over a $20 \mathrm{~m}$ grid square and representative of wildfires. However, plume diameters for the burns at Fort Benning, GA, were typically $60 \mathrm{~m}$ and the use of $25 \mathrm{~ms}^{-1}$ as an average initial vertical velocity for a $60 \mathrm{~m}$ diameter prescribed burn plume should be considered as problematic. In addition, canopy drag can further reduce the exit velocity. Forest canopies at Fort Benning ranged from open to partially closed. Positioning of field personnel away from the burns did not allow for observations. However, observations of trees rocking during plume passage at other prescribed burns are suggestive of significant momentum transfer from the plume to the crown. Furthermore, widespread crown scorch in the aftermath of prescribed burns is suggestive of significant heat transport from plume to trees. Thus the expected impact of canopies on an incipient plume would be to lower the initial vertical velocity and to reduce the initial temperature anomaly below those used for this study.

However, it is the mass flux determined by combustion equations that must be conserved. Reducing the initial average vertical velocity through canopy drag must necessarily be accompanied by a commensurate increase in initial plume diameter. That, in addition to reducing initial plume temperature anomaly through heat transfer to the crown, can lead to results that are counterintuitive because of the increased buoyancy efficiency of the larger diameter plume. For example, in this study (Figure 12), we reduced initial vertical velocity and initial plume temperature anomaly from, respectively, $25 \mathrm{~ms}^{-1}$ and $40 \mathrm{~K}$ for a $59 \mathrm{~m}$ diameter bent-over plume, to $0.5 \mathrm{~ms}^{-1}$ and $1.0 \mathrm{~K}$ for a highly-tilted plume and found the latter grew taller through an initial plume diameter seven times larger.

Thus the impact of the forest canopy may be to convert an incipient small diameter, fast-rising bent-over plume into a large diameter slow-rising highly-tilted plume capable of ascending farther than its bent-over counterpart. That Daysmoke plume heights scored slightly low in comparison with observations (refer to the discussion in reference to Figure 15) may in part be explained by our initialization for bent-over plumes. Further research will clarify this issue.

Finally, analyses just beginning of smoke observations of "strong plumes" from 55 prescribed burns should reveal the extent to which smoke from southern prescribed burns done by mass ignition penetrates above the mixing layer. In these events, a fraction of smoke emissions may not be available 
for dispersion locally downwind thus lowering threats to air quality below those predicted. However, smoke trapped within the free atmosphere above the mixing layer may be transported at different wind directions and speeds to be reintroduced into the mixing layer at unexpected locations.

\section{Appendix A}

A string of two-dimensional mass conservative sinusoidal circulation cells oriented normal to the mean wind vector within the mixing layer and with a translation speed equal to the mean wind vector describe the convective boundary layer. The cells are mutually independent-velocity amplitude, phase, wavelength and time history may differ. The equations for convective circulations at each particle location $(x, y, z)$ are:

$$
\begin{aligned}
& w_{l e}=w_{e} A \cos \left[\frac{\pi}{C h}(r-S t)\right] \sin \left(\frac{\pi z}{h}\right) \\
& U_{l e}=w_{e} C A \sin \left[\frac{\pi}{C h}(r-S t)\right] \cos \left(\frac{\pi z}{h}\right)
\end{aligned}
$$

where

$$
\begin{aligned}
& A=\sin \left[\frac{\pi}{c_{1}}\left(t+c_{2}\right)+c_{3} C_{n}\right] \\
& r=\left(x^{2}+y^{2}\right)^{1 / 2} \\
& \text { and } \\
& u_{c e}=U_{l e} u_{m} / S \\
& v_{c e}=U_{l e} v_{m} / S \\
& w_{c e}=w_{r} \frac{h}{1000}
\end{aligned}
$$

The variable, $w_{r}\left(\mathrm{~ms}^{-1}\right)$, is the reference rotor velocity for convective eddies if the mixing layer depth is $1 \mathrm{~km} ; h(\mathrm{~m})$ is the depth of the mixing layer; $u_{m}, v_{m}$, and $S$ are, respectively, the mean u-component and mean v-component for the mixing layer, and the transport wind speed. $C$ is a shape factor, here set to 1.0 so that the convective eddies will have equal horizontal and vertical dimensions. The constants, $c_{1}, c_{2}$, and $c_{3}$ are amplitude weights: $c_{1}=1200$ sets the lifetime of a convective eddy to 20 minutes, $c_{2}=2117$ and $c_{3}=23$ multiplies $C_{n}$ (a set of 10 randomly selected numbers that range from 0-9). Many choices for $c_{2}$ and $c_{3}$ are possible. The selections are made so that adjacent eddy cells will have different time and amplitude histories.

\section{Acknowledgements}

The study is funded in part of the Southern Regional Models for Predicting Smoke Movement Project (01.SRS.A.5) funded by the USDA Forest Service National Fire Plan, the Joint Fire Sciences Program of the USDA and Department of Interior (JFSP 081606 and JFSP 081604), the Department of Energy-Savannah River Operations Office through the USDA Forest Service Savannah River under Interagency Agreement DE-AI09-00SR22188, the National Research Initiative Air Quality Program of the Cooperative State Research, Education, and Extension Service, U.S. Department of Agriculture, 
(Agreement No. 2004-05240), and the U.S. Department of Defense through the Strategic Environmental Research and Development Program (SERDP-RC-1647).

\section{References}

1. SRFRR. Southern Region Forest Research Report, 7th American Forest Congress; U.S. Department of Agriculture: Forest Service, Southern Research Station, Ashville, NC, USA, February 1996.

2. Stanturf, J.A.; Wade, D.D.; Waldrop, T.A.; Kennard, D.K.; Achtemeier, G.L. Fires in southern forest landscapes. In The Southern Forest Resource Assessment; Wear, D.M., Greis, J., Eds.; Gen. Tech. Rep. SRS-53; U.S. Department of Agriculture: Forest Service, Washington, DC, USA, 2002; pp. 607-630.

3. Wade, D.D.; Brock, B.L.; Brose, P.H.; Grace, J.B.; Hoch, G.A.; Patterson, W.A., III. Fire in eastern ecosystems. In Wildland Fire in Ecosystems: Effects of Fire on Flora; Brown, J.K., Smith, J.K., Eds.; Gen. Tech. Rep. RMRS-42; U.S. Department of Agriculture, Forest Service, Rocky Mountain Research Station: Ogden, UT, USA, 2000; Volume 2, pp. 53-96.

4. Achtemeier, G.L. Effects of moisture released during forest burning on fog formation and implications for visibility. J. Appl. Meteorol. Climatol. 2008, 47, 1287-1296.

5. Achtemeier, G.L. On the formation and persistence of superfog in woodland smoke. Meteorol. Appl. 2009, 16, 215-225.

6. Naeher, L.P.; Achtemeier, G.L.; Glitzenstein, J.S.; MacIntosh, D.; Streng, D.R. Real-time and time-integrated $\mathrm{PM}_{2.5}$ and $\mathrm{CO}$ from prescribed burns in chipped and non-chipped plots-Firefighter and community exposure and health implications. J. Exposure Sci. Environ. Epidemiol. 2006, 16, 351-361.

7. Zheng, M.; Cass, G.R.; Schauer, J.J.; Edgerton, E.S. Source apportionment of $\mathrm{PM}_{2.5}$ in the Southeastern United States using solvent-extractable organic compounds as tracers. Environ. Sci. Technol. 2002, 36, 2361-2371.

8. Liu, Y.-Q.; Achtemeier, G.L.; Goodrick, S. Sensitivity of air quality simulation to smoke plume rise. J. Appl. Remote Sens. 2008, 2, 1-12.

9. Liu, Y.-Q.; Goodrick, S.; Achtemeier, G.L.; Jackson, W.A.; Qu, J.J.; Wang, W. Smoke incursions into urban areas: Simulation of a Georgia prescribed burn. Int. J. Wildland Fire 2009, 18, 336-348.

10. Liu, Y.-Q.; Achtemeier, G.L.; Goodrick, S.; Jackson, W.A. Important parameters for smoke plume rise simulation with Daysmoke. Atmos. Poll. Res. 2010, 1, 250-259.

11. Odman, M.T.; Khan, M.N.; McRae, D.S. Adaptive Grids in Air Pollution Modeling: Towards and Operational Model. In Air Pollution Modeling and its Application XIV; 1st ed.; Gryning, S.E., Schiermeier, F.A., Eds.; Kluwer Academic/Plenum Publishers: New York, NY, USA, 2001; pp. 541-549.

12. Odman, M.T.; Khan, M.N.; Srivastava, R.K.; McRae, D.S. Initial Application of the Adaptive Grid Air Pollution Model. In Air Pollution Modeling and its Application XV; 1st ed.; Borrego, C., Schayes, G., Eds.; Kluwer Academic/ Plenum Publishers: New York, NY, USA, 2002; pp. 319-328. 
13. Lee, S.; Russell, A.G.; Baumann, K. Source apportionment of fine particulate matter in the southeastern United States. J. Air Waste Manag. Assoc. 2007, 57, 1123-1135.

14. Hu, Y.M.; Odman, T.; Chang, M.E.; Jackson, W.; Lee, S.; Edgerton, E.S.; Baumann, K. Simulation of air quality impacts from prescribed fires on an urban area. Environ. Sci. Technol. 2008, 42, 3676-3682.

15. Byun, D.W.; Ching, J. Science Algorithms of the EPA Model-3 Community Multiscale Air Quality (CMAQ) Modeling System; National Exposure Research Laboratory: Research Triangle Park, NC, USA, 1999.

16. Byun, D.W.; Schere, K.L. Review of the governing equations, computational algorithms, and other components of the Models-3 Community Multiscale Air Quality (CMAQ) modeling system. Appl. Mech. Rev. 2006, 59, 51-77.

17. Herzog, M.; Graf, H.-F.; Textor, C.; Oberhuber, J.M. The effect of phase changes of water on the development of volcanic plumes. J. Volcanol. Geotherm. Res. 1998, 87, 55-74.

18. Oberhuber, J.M.; Herzog, M.; Graf, H.-F.; Schwanke, K. Volcanic plume simulation on large scales. J. Volcanol. Geotherm. Res. 1998, 87, 29-53.

19. Trentmann, J.; Andreae, M.O.; Graf, H.-F.; Hobbs, P.V.; Ottmar, R.D.; Trautmann, T. Simulation of a biomass-burning plume: Comparison of model results with observations. J. Geophys. Res. 2002, 107, 1-15.

20. Garcia-Menendez, F.; Yano, A.; Hu, Y.; Odman, M.T. An adaptive grid version of CMAQ for improving the resolution of plumes. Atmos. Poll. Res. 2010, 1, 239-249.

21. Grell, G.A.; Peckham, S.E.; Schmitz, R.; McKeen, S.A.; Wilczak, J.; Eder, B. Fully coupled online chemistry within the WRF model. Atmos. Environ. 2005, 39, 6957-6975.

22. Lavdas, L.G. Program VSMOKE-Users Manual. USDA Forest Service General Technical Report SRS-6; U.S. Department of Agriculture: Forest Service, Southern Region: Ashville, NC, USA, 1996; p. 147.

23. Goodrick, S.L.; Brenner, J. Florida's Fire Management Information System. In Proceedings of the Joint Fire Science Conference and Workshop; 15-17 June 1999; University of Idaho Press: Boise, ID, USA, 1999; Volume 1, pp. 3-12. Available online: http://jfsp.nifc.gov/conferenceproc/ Goodricketal.pdf (accessed on 12 March 2009).

24. Brenner, J.; Goodrick, S.L. Florida's Fire Management Information System. In Proceedings of EastFire Conference; George Mason University: Fairfax, VA, USA, May 2005; pp. 11-13.

25. Draxler, R.R.; Hess, G.D. Description of the Hysplit_4 Modeling System; NOAA Technical Memorandum ERL ARL-224: Washington, DC, USA, December 1997.

26. Achtemeier, G.L. Predicting dispersion and deposition of ash from burning cane. Sugar Cane 1998, 1, 17-22.

27. Achtemeier, G.L.; Adkins, C.W. Ash and smoke plumes produced from burning sugar cane. Sugar Cane 1997, 2, 16-21.

28. Briggs, G.A. Plume Rise Predictions. In Lectures on Air Pollution and Environmental Impact Analyses; American Meteorological Society: Boston, MA, USA, 1975; pp. 72-73.

29. Hess, S.L. Introduction to Theoretical Meteorology; Henry Holt \& Co.: New York, NY, USA, 1959. 
30. Cukier, R.I.; Fortuin, C.M.; Shuler, K.E.; Petschek, A.G.; Schaibly, J.H. Study of the sensitivity of coupled reaction systems to uncertainties in rate coefficients. I. Theory J. Chem. Phys. 1973, 59, 3873-3878.

31. Deeming, J.E.; Lawrence, J.W.; Fosberg, M.A.; Furman, R.W.; Schroeder, M.J. National Fire Danger Rating System; Rocky Mountain Forest and Range Experiment Station Research Paper RM-84; U.S. Department of Agriculture: Forest Service, Fort Collins, CO, USA, 1972.

32. Wade, D.D.; Lunsford, J.D. A Guide for Prescribed Fire in Southern Forests. In The Managed Slash Pine Ecosystem, 1st ed.; Stone, E.L., Ed.; School of Forest Resources and Conservation, University of Florida: Gainesville, FL, USA, 1983.

33. O’Neill, S.M.; Ferguson, S.A.; Peterson, J.; Wilson, R. The BlueSky Smoke Modeling Framework. In Proceedings of the 5th Symposium on Fire and Forest Meteorology; American Meteorological Society: Orlando, FL, USA, 16-20 November 2003.

34. Ottmar, R.D.; Anderson, G.K.; DeHerrera, P.J.; Reinhardt, T.E. Consume Version 2.1 User's Guide; Department of Agriculture: Forest Service, Pacific Northwest Research Station, Portland, OR, USA, 1999. Available online: http://www.fs.fed.us/pnw/fera/products/consume/ CONSUME21_USER_GUIDE.DOC (accessed on 19 July 2009).

35. Hao, W.M. Personal communication; 2002.

36. Sandberg, D.V.; Peterson, J. A Source Strength Model for Prescribed Fire in Coniferous Logging Slash. In Proceeding of 1984 Annual Meeting of the Air Pollution Control Association, Pacific Northwest Section, Portland, OR, USA, 1984.

37. Andrews, P.L.; Bevins, C.D.; Seli, R.C. BehavePlus Fire Modeling System, Version 3.0: User's Guide. Gen. Tech. Rep. RMRS-GTR-106WWW Revised; U.S. Department of Agriculture: Forest Service, Rocky Mountain Research Station: Ogden, UT, USA, 2005.

38. Byram, G.M. Combustion of forest fuels. In Forest Fire control and Use, Davis, K.P., Ed.; McGraw Hill: New York, NY, USA; pp. 155-182.

38. Mercer, G.N.; Weber, R.O. Fire Plumes in Forest Fires: Behavioral and Ecological Effects; Johnson, E.A., Miyanishi, K., Eds.; Academic Press: New York, NY, USA, 2001; pp. 225-256.

39. Jenkins, M.A.; Clark, T.; Coen, J. Coupling Atmospheric and Fire Models. In Forest Fires: Behavior and Ecological Effects; Johnson, E.A., Miyanishi, K., Eds.; Academic Press: San Diego, CA, USA, 2001; pp. 258-301.

40. Clements, C.B.; Zhong, S.; Goodrick, S.; Li, J.; Potter, B.E.; Bian, X.; Heilman, W.E.; Charney, J.J.; Perna, R.; Jang, M.; et al. Observing the dynamics of wildland grass fires: FireFlux-A field validation experiment. Bull. Am. Meteorol. Soc. 2007, 88, 1369-1382.

41. Cunningham, P.; Goodrick, S.L.; Hussaini, M.Y.; Linn, R.R. Coherent vertical structures in numerical simulations of buoyant plumes from wildland fires. Int. J. Wildland Fire 2005, 14, 61-75.

42. Cunningham, P.; Goodrick, S.L. High-resolution numerical models for smoke transport in plumes from wildland fires. In Remote Sensing and Modeling Applications to Wildland Fires; Qu, J.J., Riebau, A., Yang, R., Sommers, W., Eds.; Springer Publishing: New York, NY, USA, 2011; pp. $74-88$.

43. Mills, M.T. Modeling the release and dispersion of toxic combustion products from pool fires. In Proceedings International Conference on Vapor Cloud Modeling, Cambridge, MA, USA, 1987. 
44. Stern, A.C. Air Pollution Volume I; Academic Press: NewYork, NY, USA, 1968; p. 51.

45. Fisher, B.E.A.; Metcalfe, E.; Vince, I.; Yates, A. Modelling plume rise and dispersion from pool fires. Atmos. Environ. 2001, 35, 2101-2110.

46. Liu, S. Downwind Real-Time $\mathrm{PM}_{2.5}$ and $\mathrm{CO}$ Monitoring during Prescribed Forest Burns at Fort Benning, GA. Master's Thesis, University of Georgia, Athens, GA, USA, 2010.

47. Srivastava, R.K.; McRae, D.S.; Odman, M.T. An adaptive grid algorithm for air-quality modeling. J. Comput. Phys. 2000, 165, 437-472.

48. Odman, M.T.; Hu, Y. A variable time-step algorithm for air quality models. Atmos. Polution Res. 2010, 1, 229-238.

49. Anderson, G.; Sandberg, D.; Norheim, R. Fire Emission Production Simulator (FEPS) User's Guide Version 1.0; Department of Agriculture: Forest Service, Washington, DC, USA, 2004.

50. CEP. Sparse Matrix Operator Kernel Emissions Modeling System (SMOKE) User Manual; Carolina Environmental Program: Chapel Hill, NC, USA, 2003.

51. MACTEC. Documentation of the Revised 2002 Base Year, Revised 2018, and Initial 2009 Emission Inventories for VISTAS; Visibility Improvement State and Tribal Association of the Southeast (VISTAS): Ashville, NC, USA, 2005.

52. Michalakes, J.; Dudhia, J.; Gill, D.; Henderson, T.; Klemp, J.; Skamarock, W.; Wang, W. The Weather Research and Forecast Model: Software Architecture and Performance. In Proceedings of the Eleventh ECMWF Workshop on the Use of High Performance Computing in Meteorology; Zwieflhofer, W., Mozdzynski, G., Eds.; World Scientific: Singapore, 2005; pp. 156-168.

(C) 2011 by the authors; licensee MDPI, Basel, Switzerland. This article is an open access article distributed under the terms and conditions of the Creative Commons Attribution license (http://creativecommons.org/licenses/by/3.0/). 